\title{
Modulation of Angiogenic Processes by the Human Gammaherpesviruses, Epstein-Barr Virus and Kaposi's Sarcoma-Associated Herpesvirus
}

\author{
Ricardo Rivera-Soto ${ }^{1,2}$ and Blossom Damania ${ }^{1,2,3 *}$ \\ ' Lineberger Comprehensive Cancer Center, The University of North Carolina at Chapel Hill, Chapel Hill, NC, United States, \\ ${ }^{2}$ Curriculum in Genetics and Molecular Biology, The University of North Carolina at Chapel Hill, Chapel Hill, NC, \\ United States, ${ }^{3}$ Department of Microbiology and Immunology, The University of North Carolina at Chapel Hill, Chapel Hill, \\ NC, United States
}

OPEN ACCESS

Edited by:

Michael Nevels,

University of St Andrews, United Kingdom

Reviewed by:

Sayan Chakraborty, Institute of Molecular and Cell Biology

(A*STAR), Singapore

Linda F. Van Dyk,

University of Colorado Denver,

United States

Michael Lagunoff,

University of Washington,

United States

*Correspondence:

Blossom Damania

blossom_damania@med.unc.edu

Specialty section:

This article was submitted to

Virology,

a section of the journal

Frontiers in Microbiology

Received: 03 May 2019

Accepted: 20 June 2019

Published: 12 July 2019

Citation:

Rivera-Soto $R$ and Damania $B$ (2019) Modulation of Angiogenic

Processes by the Human Gammaherpesviruses, Epstein-Barr

Virus and Kaposi's

Sarcoma-Associated Herpesvirus.

Front. Microbiol. 10:1544.

doi: 10.3389/fmicb.2019.01544
Angiogenesis is the biological process by which new blood vessels are formed from preexisting vessels. It is considered one of the classic hallmarks of cancer, as pathological angiogenesis provides oxygen and essential nutrients to growing tumors. Two of the seven known human oncoviruses, Epstein-Barr virus (EBV) and Kaposi's sarcomaassociated herpesvirus (KSHV), belong to the Gammaherpesvirinae subfamily. Both viruses are associated with several malignancies including lymphomas, nasopharyngeal carcinomas, and Kaposi's sarcoma. The viral genomes code for a plethora of viral factors, including proteins and non-coding RNAs, some of which have been shown to deregulate angiogenic pathways and promote tumor growth. In this review, we discuss the ability of both viruses to modulate the pro-angiogenic process.

Keywords: angiogenesis, Epstein-Barr virus, gammaherpesviruses, Kaposi's sarcoma-associated herpesvirus, oncoviruses, vascular endothelial growth factor

\section{INTRODUCTION}

The worldwide prevalence of human cancers caused by infectious agents has been estimated to be approximately 15-20\% (Plummer et al., 2016). These infectious agents include the bacterium Helicobacter pylori, the parasite Opisthorchis viverrini and seven viruses. These human cancercausing viruses, or oncoviruses, include both DNA and RNA viruses. Since the discovery of the first human oncovirus, Epstein-Barr virus (EBV), in 1964, six additional viruses have been found to be etiologically related to several malignancies (Mesri et al., 2014). The DNA oncoviruses are EBV, Kaposi's sarcoma-associated herpesvirus (KSHV), human papillomaviruses (HPV), hepatitis $\mathrm{B}$ virus (HBV), and Merkel cell polyomavirus (MCV). The RNA oncoviruses are hepatitis $\mathrm{C}$ virus (HCV) and human T-lymphotropic virus (HTLV) type 1. Although significant improvements have been made with regards to prevention, diagnosis, and treatment of viral cancers, as evidenced by the vaccines against HBV and HPV, the multi-step process by which viruses can induce cell transformation and consequently cancer is not entirely understood. As illustrated by Mesri et al. (2014), viruses can hijack cellular processes to facilitate the dysregulated growth of cells leading to the formation of tumors. Also, to modulate cell proliferation and prevent cell death, oncoviruses promote angiogenesis, providing the tumors with a continuous supply of nutrients. 
Angiogenesis is a multi-step process that leads to the formation and growth of new blood vessels from pre-existing vessels. The angiogenic process is essential for physiological processes such as embryonic development, tissue repair during wound-healing, and the female reproductive cycle (Carmeliet and Jain, 2000). However, this process, which is tightly regulated by several pro- and anti-angiogenic factors, can be altered by cancer cells and result in enhanced tumorigenesis; the process itself is considered a hallmark of cancer (Hanahan and Weinberg, 2011). Angiogenesis occurs when the balance between proand anti-angiogenic factors is tilted toward the promotion of angiogenesis. This event is known as the "angiogenic switch," and it is an essential step during the progression and metastasis of a malignant tumor, as it can provide oxygen and nutrients required for tumor growth (Bergers and Benjamin, 2003; Baeriswyl and Christofori, 2009; Bielenberg and Zetter, 2015). The activation of the angiogenic switch can occur in both viral and nonviral cancers, but in the former, oncoviral factors are to some extent responsible for tilting the balance toward the induction of angiogenesis (Figure 1).

The angiogenic process begins with the activation of endothelial cells. This process can be intercellularly initiated from the tumor cells by the transcription factors hypoxia-inducible factors (HIF) 1 and 2 (Krock et al., 2011). First, as a tumor grows, the tumor microenvironment becomes hypoxic allowing the stabilization of HIF-1 $\alpha$. During normoxic conditions, prolylhydroxylases (PHDs) hydrolyze HIF-1 $\alpha$, which can then be recognized by the von Hippel-Lindau (VHL) tumor suppressor. This leads to the ubiquitin-mediated degradation of HIF-1 $\alpha$. However, in the absence of oxygen (or during oncogenic activation), PHDs cannot hydrolyze HIF-1 $\alpha$, which result in HIF- $1 \alpha$ translocating to the nucleus and dimerizing with HIF$1 \beta$ to activate the HIF-responsive element (HRE)-containing promoters. Several pro- and anti-angiogenic factors including vascular endothelial growth factor (VEGF), fibroblast growth factors (FGF), platelet-derived growth factor (PDGF), and several

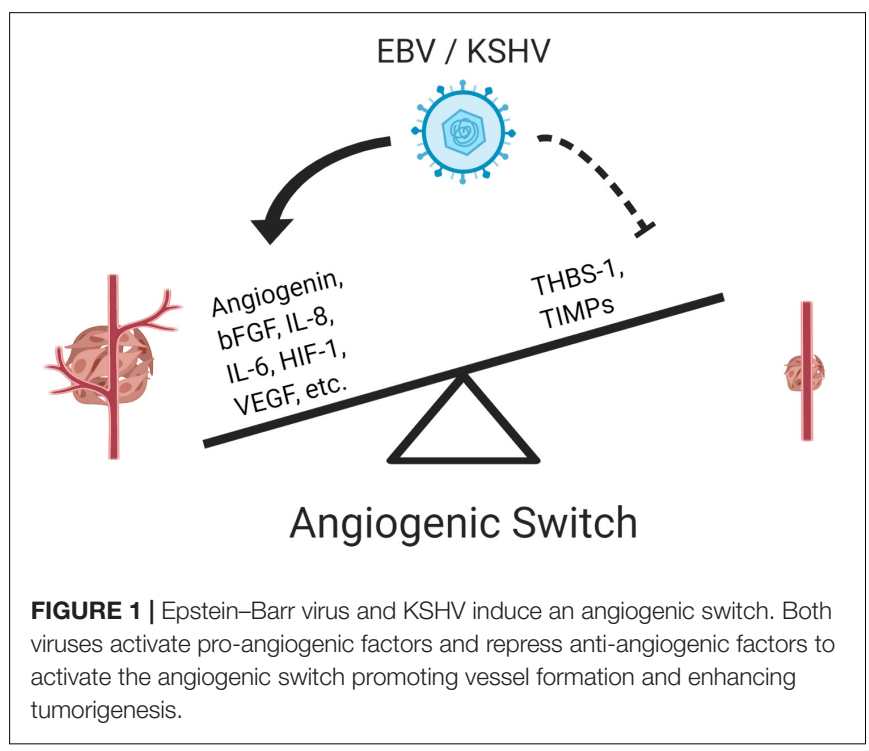

interleukins (IL) such as IL-6 and IL-8 are induced by HIF-1 (Krock et al., 2011).

Following the induction of expression, these pro-angiogenic factors are secreted from the tumor cells and intercellularly bind and activate their respective receptors in endothelial cells (Figure 2). Activation of the receptors such as VEGFR-2, FGFR, and Tie-2, stimulate the modulation of several signaling pathways including phosphatidylinositol 3-kinase (PI3K)/Akt, mitogenactivated protein kinase (MAPK)/extracellular-regulated kinase (ERK), and Janus kinase (JAK)/signal transducer and activator of transcription (STAT; Cross and Claesson-Welsh, 2001). This in turn further enhance angiogenesis by promoting cell survival, proliferation, and invasion (Cross and Claesson-Welsh, 2001).

In addition to the tumor cells, the endothelial sprouting cells forming the new vessels induce the expression and activation of pro-migratory factors such as matrix metalloproteinase enzymes (MMPs; described below). MMPs degrade extracellular matrix components and facilitate cell movement. The expansion and cell movement allow for the branching of blood vessels. Importantly, the secretion of pro-angiogenic factors by the tumor cells can also act as an attractant for the proliferating endothelial cells and recruitment of immune cells (Weis and Cheresh, 2011). Following the formation of the new blood vessel, pericytes are recruited and attached to newly matured endothelial cells (Weis and Cheresh, 2011).

However, due to the fast and uncontrolled growth, and continuous stimulation associated with pathological angiogenesis, these tumorigenic blood vessels acquire an aberrant morphology that includes excessive branching with defective basement membrane and uneven pericyte coverage (Azzi et al., 2013). These effects contribute to the tortuosity and leakiness of tumor-associated blood vessels facilitating metastasis (Azzi et al., 2013). Furthermore, the expansion of these new blood vessels allows for the formation of networks with existing vessels in a process known as anastomosis.

Two of the seven human oncoviruses, EBV and KSHV, belong to the subfamily of Gammaherpesvirinae. Both viruses have been identified as the etiologic agents of several malignancies that are dependent on the expression of pro-angiogenic factors. Though $\mathrm{KSHV}$ was discovered just 25 years ago, KSHV, as a potent inducer of angiogenesis, has been described to a greater extent than has EBV since Kaposi's sarcoma, the cancer associated with $\mathrm{KSHV}$, is one of the most angiogenic human tumors and is driven by KSHV-infected endothelial cells. In this review, we will describe the current knowledge of how both viruses, as a whole or via their proteins and non-coding RNAs, modulate angiogenic processes and how these might contribute to virusinduced tumorigenesis.

\section{EPSTEIN-BARR VIRUS}

Epstein-Barr virus (EBV) is a ubiquitous $\gamma-1$ herpesvirus that infects approximately $95 \%$ of the world's population. EBV is associated with several malignancies that include B-, T-, and Natural Killer-cell lymphomas, post-transplant lymphoproliferative disease (PTLD), endemic Burkitt's 


\section{Extracellular}

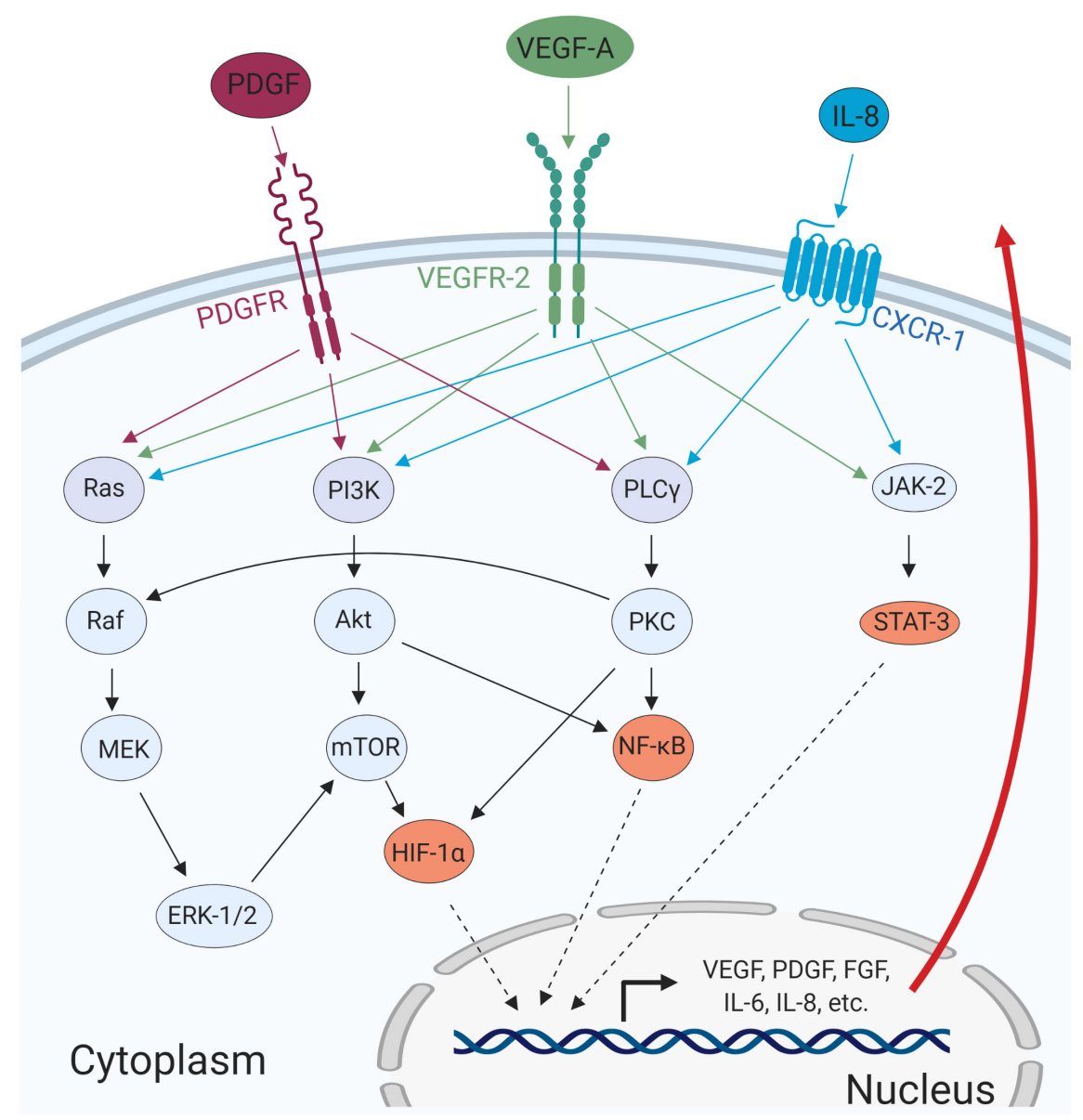

FIGURE 2 | Major cellular pathways converge to promote angiogenic processes. The cellular receptors PDGFR, VEGFR-2, and CXCR-1, are activated upon ligand-binding and mediates activation of major signaling pathways such as MAPK/ERK, PI3K/Akt, PLC $\gamma /$ PKC, and JAK/STAT. The activation of these pathways results in the transcription of pro-angiogenic genes that can promote cell migration, invasion, and angiogenesis in autocrine and paracrine manners.

lymphoma, a subset of Hodgkin's lymphomas, and the epithelial malignancies nasopharyngeal carcinoma (NPC) and gastric carcinoma (Young et al., 2016). Similar to other herpesviruses, EBV infection induces the formation of a viral episome that is tethered to the host genome and facilitates the establishment of a latent lifecycle.

Epstein-Barr virus induces different latency programs in infected cells. For example, in vitro, EBV infection transforms resting B-cells into immortalized lymphoblastoid cell lines (LCLs) that expresses several viral genes including all six Epstein-Barr nuclear antigens (EBNAs), latent membrane protein (LMP) 1, LMP2A and 2B, and EBV-encoded RNAs (EBER) 1 and 2. This type of latency, known as latency III, promotes the proliferation of the infected B-cells, allowing the replication of not only the host genome but also the viral episome. In vivo, latency III is associated with PTLD and diffuse large B-cell lymphomas (Young et al., 2016). This EBV-mediated proliferation mimics B-cell development in which cells enter the germinal center, but it is highly immunogenic. Instead, a less immunogenic latency program (latency II), as seen in the EBV-associated classical Hodgkin's lymphoma, consists in the expression of EBNA1, LMP1, LMP2A and 2B, and EBER1-2. Importantly, this type of latency is also seen in the EBV-induced epithelial cancers, NPC, and gastric carcinomas.

Memory B-cells are thought to be the reservoir for EBV, and in these cells, the virus induces two distinct programs, latency 0 and latency I. In latency 0 , which is specific to resting B-cells, only EBER1-2 are expressed. On the other hand, a dividing memory B-cell experiences latency I, in which EBER1-2 and EBNA1 are expressed. The expression of EBNA1 is sufficient for the replication and maintenance of the viral episome. Burkitt's lymphoma shows a latency-I expression profile. A specific latency pattern is not needed for EBV to induce cell transformation since the malignant cells show different gene expression profiles (Young et al., 2016).

Several groups have explored the effect of EBV infection in inducing angiogenesis. For example, infection of epithelial cells, the cells of origin for EBV-induced gastric and nasopharyngeal 
carcinomas, induces the formation of vascular mimicry that correlates with tumor growth (Xiang et al., 2018). Vascular mimicry is the process by which non-endothelial cells form tubular networks and allow for blood flow independent of endothelial cells (Dunleavey and Dudley, 2012). Furthermore, EBV-positive gastric carcinomas show an aberrant regulation of epigenetic markers of enhancers associated with angiogenic processes; these malignancies also display silencing of tumors suppressors and anti-angiogenic factors such as phosphatase and tensin homolog (PTEN) and thrombospondin (THBS) 1 (Kang et al., 2002; Okabe et al., 2017).

Further evidence has demonstrated that EBV-positive NPC cells are more tumorigenic and angiogenic in vivo than EBVnegative NPC cells (Ye et al., 2018). EBV is associated with high levels of VEGF and reduced survival of Hodgkin's lymphoma patients (Koh et al., 2018). Angiogenic processes are also involved in the development of B-cell lymphomas in mice caused by the engraftment of EBV-transformed LCLs (Woodford et al., 2004). These studies outline a role for EBV in inducing proangiogenic processes that enhance tumorigenesis. Elucidating the process by which the individual viral proteins and non-coding RNAs modulate angiogenesis is essential for developing effective therapies. We describe a few of these viral factors below.

\section{Latent Membrane Protein 1}

A major oncogenic protein of EBV is LMP1. LMP1 has transforming properties in cultured cell lines, and it is expressed in most EBV-associated cancers (Wang et al., 1985). LMP1, a mimic of cellular CD40, is a constitutively active member of the tumor necrosis factor receptor (TNFR) family with the ability to activate signaling pathways including NF- $\kappa \mathrm{B}, \mathrm{PI} 3 \mathrm{~K} / \mathrm{Akt}$, MAPK/ERK, JAK/STAT, and c-Jun N-terminal kinase (JNK) (Figure 3; Mosialos et al., 1995; Devergne et al., 1996; Gires et al., 1999; Dawson et al., 2003; Mainou et al., 2005). Activation of these pathways has multiple effects in the infected cells, including the modulation of apoptosis, cell migration, cell cycle progression, and angiogenesis (Table 1). One line of evidence that LMP1 is involved in inducing angiogenesis can be demonstrated by introducing LMP1 into LMP1-negative NPC cells. The co-culture of LMP1-expressing NPC and human umbilical vein endothelial cells (HUVECs) induces the formation of endothelial cell tubular structures on Matrigel, demonstrating the contribution of the viral protein to the angiogenic process (Yang et al., 2015).

In NPC tumor tissues, VEGF is highly expressed, and it correlates with microvessel density (Wakisaka et al., 1999; Guang-Wu et al., 2000; Qian et al., 2000). Moreover, through the activation of VEGF/VEGFR-1, LMP1 induces vascular mimicry, which is associated with poorer prognosis (Xu et al., 2018). Additionally, in diffuse large B-cell lymphoma patients, EBV infection, and VEGF-A expression associates with aggressive subtypes and shorter survival times (Paydas et al., 2008). As mentioned in the introduction, induction of HIF proteins and VEGF is one of the essential steps for the promotion of angiogenesis; thus, it is not surprising that several signaling pathways converge to induce the expression and stabilization of these proteins (Carmeliet, 2005; Krock et al., 2011). In nasopharyngeal epithelial cells, LMP1 induces the expression of HIF- $1 \alpha$ and VEGF by activating MAPK/ERK, JNKs and JAK/STAT signaling pathways (Gires et al., 1999; Wakisaka et al., 2004; Wang et al., 2010; Yang et al., 2015). Thus, LMP1 activates multiple signaling pathways to induce VEGF, which is usually associated with more aggressive disease.

Furthermore, LMP1 induces the production of reactive oxygen species (ROS) such as $\mathrm{H}_{2} \mathrm{O}_{2}$, which mediates the stabilization and translocation of HIF-1 $\alpha$ (Chandel et al., 2000; Wakisaka et al., 2004). Moreover, LMP1 induces the activation of HIF- $1 \alpha$ and PI3K/Akt through the expression of the chemokine (C-C motif) ligand (CCL) 5 (also known as RANTES; Buettner et al., 2007; Ma et al., 2018). Also, LMP1 can upregulate the levels of the E3 ubiquitin ligase Siah-1 (Kondo et al., 2006), which targets the HIF-1 $\alpha$ negative regulators' PHDs 1 and 3 for degradation (Nakayama et al., 2004). Therefore, LMP1 increases the levels of HIF- $1 \alpha$ not only by promoting its expression but also by downregulating the repressors involved in the control of HIF- $1 \alpha$.

For proper induction of angiogenesis, LMP1 requires the

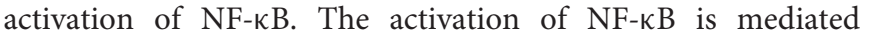
by LMP1's C-terminal-activating regions, CTAR1 and CTAR2, which can constitutively associate with tumor necrosis factor receptor-associated factors (TRAFs). This interaction leads to the activation of the NF- $\kappa$ B signaling cascade, which promotes the expression of genes with multiple functions, including induction of angiogenesis. One angiogenic factor induced by LMP1 that requires NF- $\kappa \mathrm{B}$ is cyclooxygenase-2 (COX-2). Activation of COX-2 in LMP1-expressing NPC cells leads to an increase in the production of the angiogenic factors prostaglandin E2 (PGE2) and VEGF (Murono et al., 2001). Furthermore, in NPC tissues, the expression of COX-2 correlates with LMP1, whereas LMP1negative NPC infrequently expresses COX-2 (Murono et al., 2001; Fendri et al., 2008).

Similar to COX-2, the expression of IL-8 is, to some extent,

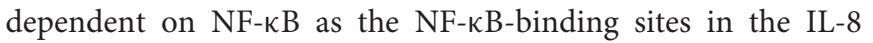
promoter are necessary for LMP1-induced expression (Yoshizaki et al., 2001). Interleukin-8 (also known as CXCL-8) is a proinflammatory chemokine that has the pro-angiogenic activity of activating CXCR-1 (Figure 2; Koch et al., 1992; Waugh and Wilson, 2008; Shi and Wei, 2016). Importantly, the expression of LMP1 also correlates with IL-8 in NPC tumor tissues, and it is associated with the formation of microvessels and poor prognosis in NPC patients (Xie et al., 2010).

Furthermore, LMP1 induces the expression of the proangiogenic factors FGF-2 and epidermal growth factor (EGF) receptor (EGFR) (Miller et al., 1995; Wakisaka et al., 2002; Thornburg and Raab-Traub, 2007; Kung and Raab-Traub, 2008; Lo et al., 2015). This induction is also mediated through the activation of NF- $\kappa \mathrm{B}$, and the activation of FGF-2/FGFR-1 signaling is important for the transformation of NPC cells (Lo et al., 2015). FGF-2, which can also be present in LMP1-induced exosomes, can act in both paracrine and autocrine manners to induce the expression and secretion of VEGF, promoting the activation of endothelial cells (Seghezzi et al., 1998; Ceccarelli et al., 2007). In addition to NF- $\mathrm{B}$, STAT-3, and protein kinase $\mathrm{C}$ gamma $(\mathrm{PKC} \gamma)$ are essential for the LMP1-CTAR1-induced augmentation of EGFR activation (Kung and Raab-Traub, 2008). 
TABLE 1 | Major pro- and anti-angiogenic factors modulated by EBV viral factors.

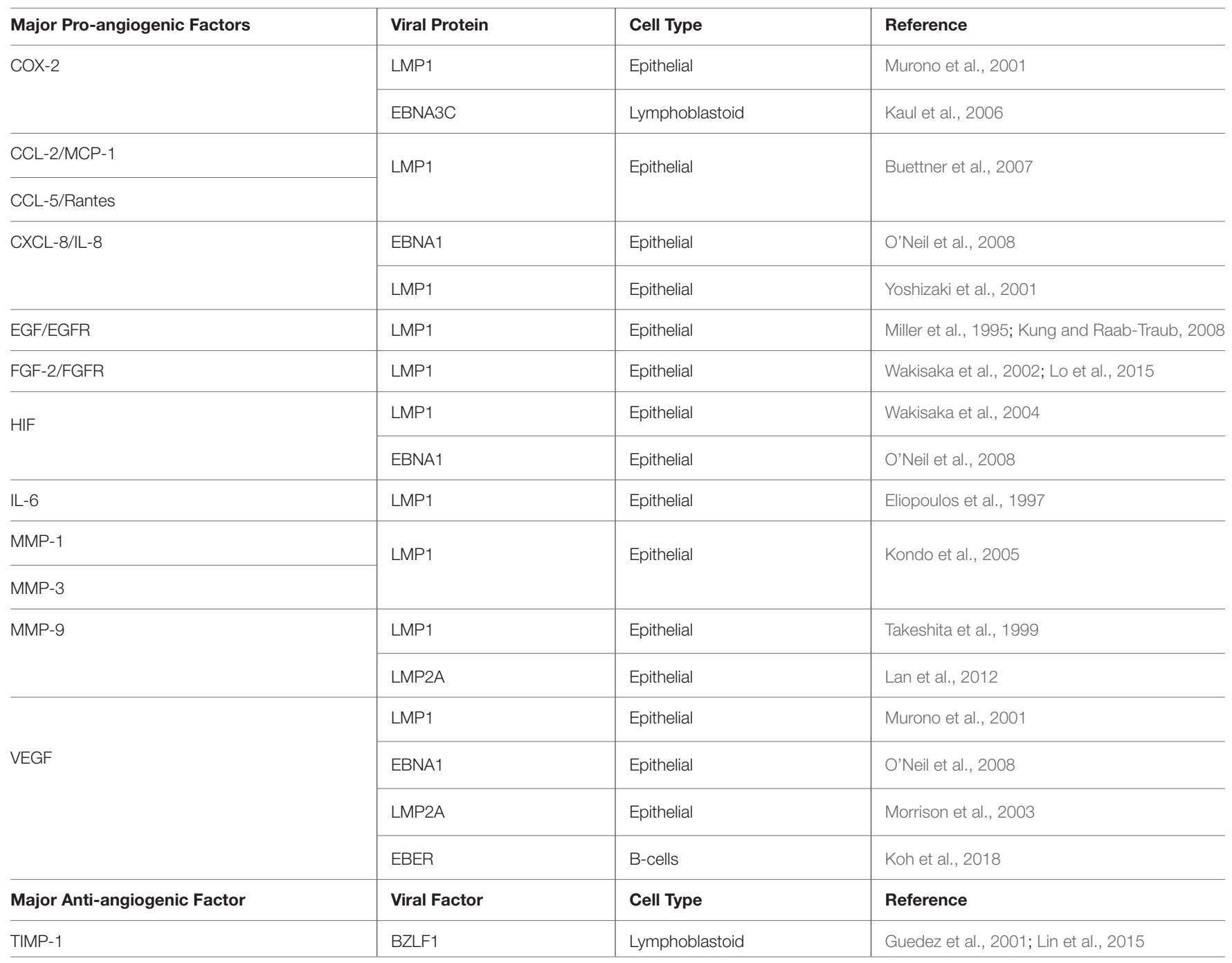

It is possible that through the activation of EGFR in NPC cells, EBV enhances calcium signaling that promotes VEGF expression (Ye et al., 2018). Together, these studies suggest that induction of both FGFR and EGFR contributes to LMP1mediated angiogenesis.

An additional pro-angiogenic growth factor that LMP1 induces in epithelial cells is the hepatocyte growth factor receptor (HGFR, also known as c-Met). The LMP1-induced expression of c-Met is mediated through activation of the Ets-1 transcription factor (Horikawa et al., 2001). The expression of c-Met, LMP1, and Ets-1 are correlated in NPC tumor tissues. c-Met plays an important role in both angiogenesis and metastasis, and it is usually associated with poor prognosis (Ding et al., 2003; You and McDonald, 2008). Activation of c-Met in endothelial cells can lead to an increase of VEGF and suppression of the anti-angiogenic protein THBS-1, thus enhancing the angiogenic process (Zhang et al., 2003). In EBV-positive gastric carcinomas, the overexpression of c-Met may contribute to angiogenesis. However, the EBV protein that induces c-Met may not be LMP1, as it is rarely expressed in these cells (Kijima et al., 2002; Luo et al., 2006). Thus, EBV, through LMP1 and other viral genes, induces several growth factor receptors that contribute to the promotion of angiogenesis.

Matrix metalloproteinase enzymes (MMPs) are a group of zinc-containing endopeptidases capable of degrading ECM components and mediating pericyte detachment from vessels undergoing angiogenesis (Rundhaug, 2005). This group of proteins is essential for angiogenesis, but they also play a critical role in metastasis by cleaving the ectodomain of vascular endothelial (VE)-cadherin that maintains cell-cell adhesions (Shiomi and Okada, 2003). The expression of MMP-9 is induced by the CTAR1-2 domains of LMP1 (Yoshizaki et al., 1998; Takeshita et al., 1999). Importantly, the NF- $\kappa$ B and AP-1 binding sites of the MMP-9 promoter are necessary for MMP9 expression, suggesting the involvement of both pathways. In addition to MMP-9, MMP-1 is also highly expressed in NPC and modulated by LMP1 (Lu et al., 2003; Kondo et al., 2005). Interestingly, a polymorphism in the MMP-1 promoter of NPC 
cells creates an Ets binding site, and its high expression is associated with poor prognosis (Kondo et al., 2005). In addition to increasing MMP-1 levels directly, LMP1 can also increase the production of MMP-3, which cleaves and consequently activates MMP-1. Expression of both MMP-1 and MMP-3 is dependent on $\mathrm{AP}-1$, and Ets transcription factors, as mutations to their binding sites or co-expression of double-negative mutants perturb their expression (Kondo et al., 2005).

LMP1 also induces the expression of other pro-migratory factors. Among these, is Twist, which increases cell migration and drives the epithelial-mesenchymal transition (Horikawa et al., 2007). Clinical samples show a high correlation between Twist and LMP1 expression in metastatic NPC (Horikawa et al., 2007). In addition to being a master regulator in embryogenesis (a process that requires extensive pro-angiogenic activity), Twist has been shown to mediate angiogenesis in an in vivo model of breast cancer (Mironchik et al., 2005). In NPC tissues, LMP1 induces the receptor for advanced glycation end products (RAGE; Tsuji et al., 2008). High microvessel counts, as determined by von Willebrand factor (vWF) staining, are associated with high levels of RAGE, LMP1, and lymph node metastasis, suggesting a role for RAGE in EBV-induced angiogenesis (Yamagishi et al.,
1997; Tsuji et al., 2008). Furthermore, LMP1 promotes the expression of the soluble TNFR Decoy receptor (Dcr) 3, which in endothelial cells promotes angiogenesis by inhibiting TNFlike molecule 1A (TL1A; Ho et al., 2009). The expression of Dcr3 in NPC cells is associated with increased cell migration and invasion (Ho et al., 2009). In order for proper angiogenesis to occur, cells must migrate and invade through the extracellular matrix, and LMP1 induces the expression of several factors that facilitate this process.

Tumor viruses such as EBV can induce the secretion of exosomes that facilitate intercellular communication (KeryerBibens et al., 2006; Meckes et al., 2010). Exosomes are 40- to 100$\mathrm{nm}$ secreted endosomal vesicles containing proteins, mRNAs, and microRNAs that can influence the tumor microenvironment (Schorey and Bhatnagar, 2008). Exosomes released from LMP1positive NPC cells contain LMP1, cellular miRNAs, EBERs, signal transduction proteins and HIF-1 $\alpha$ (Ceccarelli et al., 2007; Meckes et al., 2010; Aga et al., 2014; Yoon et al., 2016). The enclosed proteins maintain their activity and can increase the pathogenicity of the recipient cells (e.g., endothelial cells) by promoting processes such as migration, invasion, and angiogenesis (Meckes et al., 2010). Retinal pigmental epithelial

\section{Extracellular}

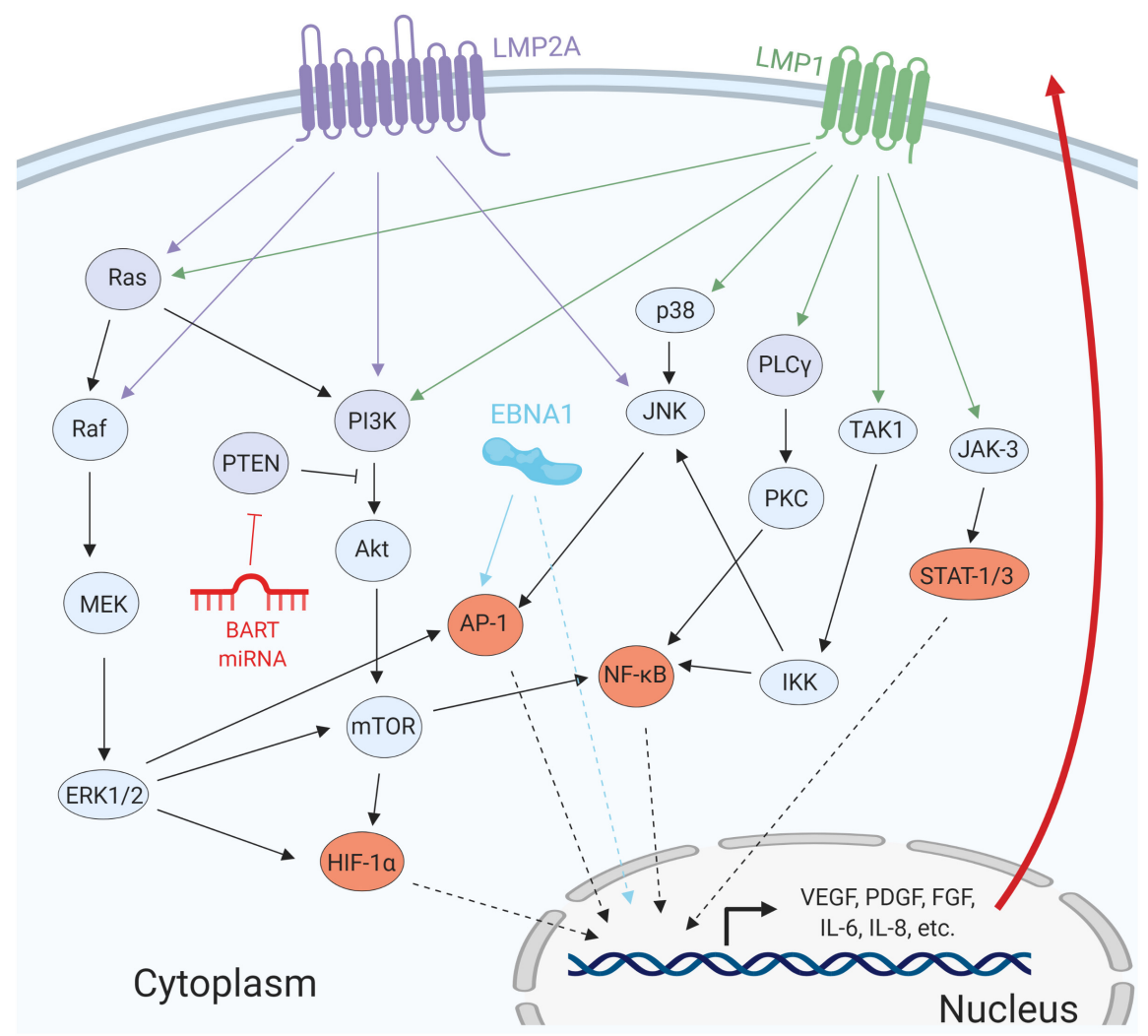

FIGURE 3 | Epstein-Barr virus proteins and miRNAs promote angiogenesis by activating several cellular signaling pathways. The viral transmembrane proteins LMP1 and LMP2A promote the activation of several signaling pathways including MAPK/ERK, PI3K/AKt, PLC $\gamma /$ PKC, and JAK/STAT. EBNA1 directly promotes activation of pro-angiogenic genes and transcription factors such as AP-1. The BART miRNA targets the negative regulator of PI3K/Akt, PTEN. Activation of these signaling pathways results in the promotion of pro-survival and pro-angiogenic factors. 
cells grown in the presence of exosomes from the EBV-positive B-cell line Raji have higher levels of VEGF which was due in part to the cellular miR-155 contained in those vesicles (Yoon et al., 2016). It has been demonstrated that LMP1 induces expression of miR-155 by activating NF- $\kappa$ B signaling (Gatto et al., 2008; Lu et al., 2008). Secretion of exosomes provides a mechanism by which viral cancers can influence the conditions of the tumor microenvironment without the need for viral propagation.

Altogether, these studies support a model in which LMP1 promotes the activation of an arsenal of factors that contribute to EBV-induced angiogenesis.

\section{Latent Membrane Protein 2A}

The transmembrane protein LMP2A is expressed during latency II and III and induces ligand-independent activation of the SrC and Syk family of proteins by mimicking an active B-cell receptor (Portis and Longnecker, 2004). This interaction mediates the activation of Ras, PI3K, and JNK (Figure 3). Consequently, expression of LMP2A in murine B-cells drives the expression of genes promoting cell proliferation and survival that are common in EBV-positive Hodgkin's lymphoma cells (Portis et al., 2003). These observations suggest that LMP2A may play a significant role in Hodgkin's lymphoma development. Similarly, epithelial cells expressing LMP2A have higher PI3K/Akt and Wnt signaling activity, which can result in the expression of VEGF (Morrison et al., 2003). Notch activation, which has been shown to have pro-angiogenic effects, can be promoted by LMP2A-mediated induction of Notch ligand Delta and transcription factor Hes1 (Sakakibara and Tosato, 2009). In addition to LMP1, LMP2A also contributes to vascular mimicry of EBV-infected epithelial cells. However, in contrast to LMP1, LMP2A-mediated induction of vascular mimicry is independent of VEGF but relies on HIF- $1 \alpha$ through the activation of PI3K/Akt signaling (Xiang et al., 2018). Additionally, LMP2A promotes the invasiveness of NPC cells through the ERK-dependent expression of MMP-9 (Lan et al., 2012). Thus, LMP2A contributes to EBV-induced angiogenesis and may be an essential player for lymphomagenesis.

\section{EBV Nuclear Antigen 1}

The EBV nuclear antigen (EBNA) 1 is an essential protein necessary for viral maintenance and replication (reviewed in Wilson et al., 2018). It plays the essential role of tethering the viral episome to the host genome and acting as a modulator of expression of viral and cellular genes (Wood et al., 2007; Frappier, 2015). Through the modulation of gene expression, EBNA1 enhances STAT-1 activation and interferes with transforming growth factor (TGF)- $\beta$ signaling as TGF- $\beta 1$-responsive genes are repressed in EBNA1-expressing cells (Wood et al., 2007). Furthermore, EBNA1 promotes the activation of the AP-1 transcription factor in epithelial cells, resulting in the expression of its pro-angiogenic target genes including IL-8, VEGF, and HIF-1 $\alpha$ (O'Neil et al., 2008). The expression and secretion of IL-8 and VEGF from EBNA-1 expressing epithelial cells induces angiogenic phenotypes in an intercellular manner (O’Neil et al., 2008). Thus, in addition to being essential for viral maintenance,
EBNA1 is also involved in the modulation of the proangiogenic process.

\section{EBV Nuclear Antigen 3}

EBNA3 contains three spliced variants (A, B, and C) that are encoded in tandem and expressed during latency III. These variants are a family of transcription co-regulators that do not bind directly to DNA but instead use other proteins to modulate transcription. For example, EBNA3C interacts with the nucleoside diphosphate kinase $(\mathrm{Nm} 23-\mathrm{H} 1)$ to induce the expression of the pro-angiogenic factor COX-2 in an NF-кBdependent manner (Kaul et al., 2006). Importantly, expression of EBNA3C alone does not increase the levels of COX2 , demonstrating the requirement for an additional cofactor. EBNA3C also modulates JAK/STAT signaling by upregulating STAT-3 expression and downregulating the negative regulator of STAT-3, protein inhibitor of activated STAT 1 (PIAS1; Zhao et al., 2011). Although not much is known about EBNA3 and angiogenesis, these studies have demonstrated a possible role of the viral protein in contributing to EBVinduced tumorigenesis.

\section{EBV Non-coding RNAs}

The EBV-encoded small RNAs (EBERs) 1 and 2 are highly abundant viral transcripts in latently infected cells that are used for the detection of EBV-infected tissues (reviewed in Iwakiri and Takada, 2010). Although they are not essential for the in vitro transformation of B-cells, several studies have shown that they are involved in preventing apoptosis while promoting cell proliferation, tumor growth, and possible angiogenesis (Swaminathan et al., 1991; Laing et al., 2002; Nanbo et al., 2002; Iwakiri et al., 2003). With regards to angiogenesis, EBER expression has been directly correlated to VEGF expression in Hodgkin's lymphoma patients (Koh et al., 2018). Importantly, EBER-containing exosomes secreted from NPC cells can be transferred to surrounding endothelial cells and singularly induce the expression of vascular cell adhesion molecule (VCAM) 1, which promotes angiogenic processes in in vitro and in vivo models (Cheng et al., 2019).

Epstein-Barr virus encodes at least 48 mature miRNAs from two different regions of the viral genome. Four are produced from the BamHI fragment $\mathrm{H}$ rightward reading frame (BHRF) 1 gene and the rest from $\mathrm{BamHI}$ fragment A rightward transcript (BART; Chen et al., 2010). EBV miRNAs can target both cellular and viral mRNAs to modulate the host immune response and maintain viral latency (reviewed in Wang et al., 2018). Additionally, several lines of evidence suggest that miRNAs are involved in promoting survival and tumorigenesis. In NPC cells, the miR BART1 targets both AMP-activated protein kinase (AMPK) $\alpha 1$ and PTEN, which results in the activation of downstream targets including mammalian target of rapamycin (mTOR) and MAPK/ERK (Cai et al., 2015; Lyu et al., 2018). Activation of these pathways promotes epithelial to mesenchymal transition and enhances glycolysis, cell migration, invasion, and angiogenesis. Altogether, these studies demonstrate that both EBERs and EBV miRNAs might contribute to EBV-induced 
angiogenesis by acting in a paracrine manner or by suppressing tumor suppressors.

\section{BZLF1 and BRLF1}

The BZLF1 (Zta) and BRLF1 (Rta) viral transcription factors are two lytic proteins essential for the induction of the lytic cycle. Although both genes are dispensable for immortalization of primary B-cells in vitro, they are important for promoting tumor growth of LCLs in severe combined immunodeficient mice (Hong et al., 2005a). In contrast to LCLs infected with WT EBV, cells infected with BZLF1- or BRLF1-deleted virus have lower levels of VEGF secretion, and supernatant from these cells has reduced ability to promote tubule formation in endothelial cells (Hong et al., 2005b). Even though most EBV-associated tumor cells have the virus in latent form, it is not uncommon to find a small subset of lytically infected cells. Several lines of evidence have suggested that this small percentage of cells is necessary for proper tumor formation, as they contribute in a paracrine manner by secreting growth factors (Ma et al., 2011; McHugh et al., 2017; Cohen et al., 2018).

In addition to promoting VEGF, BZLF1 induces the expression of tissue inhibitor of metalloproteinase (TIMP) 1 , which is involved in the modulation of MMPs but also plays a role in viral tumorigenesis by acting as an antiapoptotic protein (Guedez et al., 2001; Lin et al., 2015). Thus, these two lytic proteins may contribute to EBV-induced tumorigenesis by modulating the expression of factors involved in angiogenesis.

\section{KAPOSI'S SARCOMA-ASSOCIATED HERPESVIRUS}

Kaposi's sarcoma-associated herpesvirus is a $\gamma-2$ herpesvirus associated with three human malignancies: the endothelial cell-driven cancer Kaposi's sarcoma (KS) and two B-cell lymphoproliferative diseases: Multicentric Castleman's disease (MCD) and primary effusion lymphoma (PEL). Like EBV, KSHV infection is lifelong, and diseases mostly arise in the context of immunosuppression (Dittmer and Damania, 2016). Following infection, the viruses establish a latent cycle expressing only a handful of genes. The latency locus includes open reading frame (ORF)71, ORF72, ORF73, ORF K12, and miRNAs. Upon induction of lytic replication, which is controlled by the protein product of ORF50, transcription of the viral genome occurs in an orderly fashion (Dittmer and Damania, 2016). As discussed with regard to $\mathrm{EBV}$, although $\mathrm{KSHV}$-associated tumor cells are latently infected, a subset of them undergo lytic replication, which is hypothesized to contribute to viral tumorigenesis by providing growth factors in a paracrine manner (Mesri et al., 2014). Many of these pro-tumorigenic factors are directly linked to the induction of angiogenic processes (Dimaio and Lagunoff, 2012; Purushothaman et al., 2016).

Initial studies in $\mathrm{KS}$ and PEL illustrated the importance of tumor cells in inducing VEGF and VEGFR (Brown et al., 1996; Cornali et al., 1996; Flore et al., 1998; Aoki and Tosato, 1999; Masood et al., 2002). VEGF can enhance the infectivity of the virus, and its expression is increased as early as 30 min post-infection, suggesting a role in mediating infection (Sivakumar et al., 2008). Following infection, KSHV triggers the reactivation of silenced genes such as PAX2. Generally restricted to embryogenesis, KSHV-mediated induction of PAX2 leads to the expression of CCL-2 and Akt, which contributes to the angiogenic and invasiveness potential of endothelial cells (Fonsato et al., 2008). Furthermore, KSHV-infected endothelial cells have increased PI3K/Akt activity, which is a major contributor to viral-induced tubule formation (Wang and Damania, 2008). Additionally, KSHV-infected endothelial cells express and secrete many other pro-angiogenic factors. Some of these proteins include HIF- $1 \alpha$, HIF- $2 \alpha$, IL-8, GRO- $\alpha$, CCL-2, and angiopoietin-2 (Table 2; Lane et al., 2002; Carroll et al., 2006; Caselli et al., 2007, 2012; Ye et al., 2007; Fonsato et al., 2008).

The demand for oxygen and nutrients during angiogenesis triggers ROS, which in turn contributes to the pathological process (Kim and Byzova, 2014). Consequently, KSHV tumor cells rely on the production of ROS, as treatment with antioxidants represses pro-angiogenic factors and decreases the formation of KS-like tumors in mice (Ma et al., 2009, 2013). For example, in an NF-кB-dependent but HIF-1 $\alpha$-independent manner, ROS and hypoxic conditions induce the expression of galectin-1, driving angiogenic phenotypes in KS-like tumors (Croci et al., 2012). Moreover, the redox functions of apurinic/apyrimidinic endonuclease (APE) 1, which can affect several types of transcription factors, are involved in KSHVinduced angiogenesis (Zhong et al., 2017). Thus, the production of ROS by KSHV-infected endothelial cells is needed for the formation of KS-like tumors and their vasculature.

Kaposi's sarcoma-associated herpesvirus infection of endothelial cells promotes the expression of integrin subunits $\beta 1$ and $\beta 3$ (Dyson et al., 2007; DiMaio et al., 2011). In endothelial cells, integrins (e.g., $\alpha \mathrm{V} \beta 1$ and $\alpha \mathrm{V} \beta 3$ ) play a role in KSHV entry by binding to glycoprotein B (Kumar and Chandran, 2016). Activation of integrins such as $\alpha \mathrm{V} \beta 3$ induces phosphorylation of focal adhesion kinase (FAK) and tyrosine kinase Src, promoting the release of stored angiogenin (Ang) 2 (Ye et al., 2013). Ang-2 plays an essential role in the vasculature of KSHV tumors by serving as a ligand for the tyrosine kinase receptor Tie-2 (Yu et al., 2016). Activation of Tie-2 enhances VEGF signaling and induces activation of PI3K/Akt and MAPK/ERK pathways (Thurston and Daly, 2012). Thus, in endothelial cells, integrins facilitate viral binding and entry, and they are also involved in cell migration and angiogenesis.

Furthermore, KSHV infection of endothelial cells promotes cell migration through the induction of MMP-1, MMP-2, and MMP-9 (Qian et al., 2007). This process is facilitated in part by the KSHV-induced activation of the AP-1 transcription factor. The disruption of cell-cell junctions enables cell migration, and in endothelial cells promotes vascular permeability. KSHV induces this process by modulating the expression or phosphorylation of VE-cadherin (Samaniego et al., 1998; Qian et al., 2008; Guilluy et al., 2011). Importantly, the viral proteins K1, K5, and vGPCR are significant contributors to these processes during both latent and lytic phases (Figure 4; Mansouri et al., 2008; Dwyer et al., 2011; Guilluy et al., 2011). 
TABLE 2 | Major pro- and anti-angiogenic factors modulated by KSHV viral factors

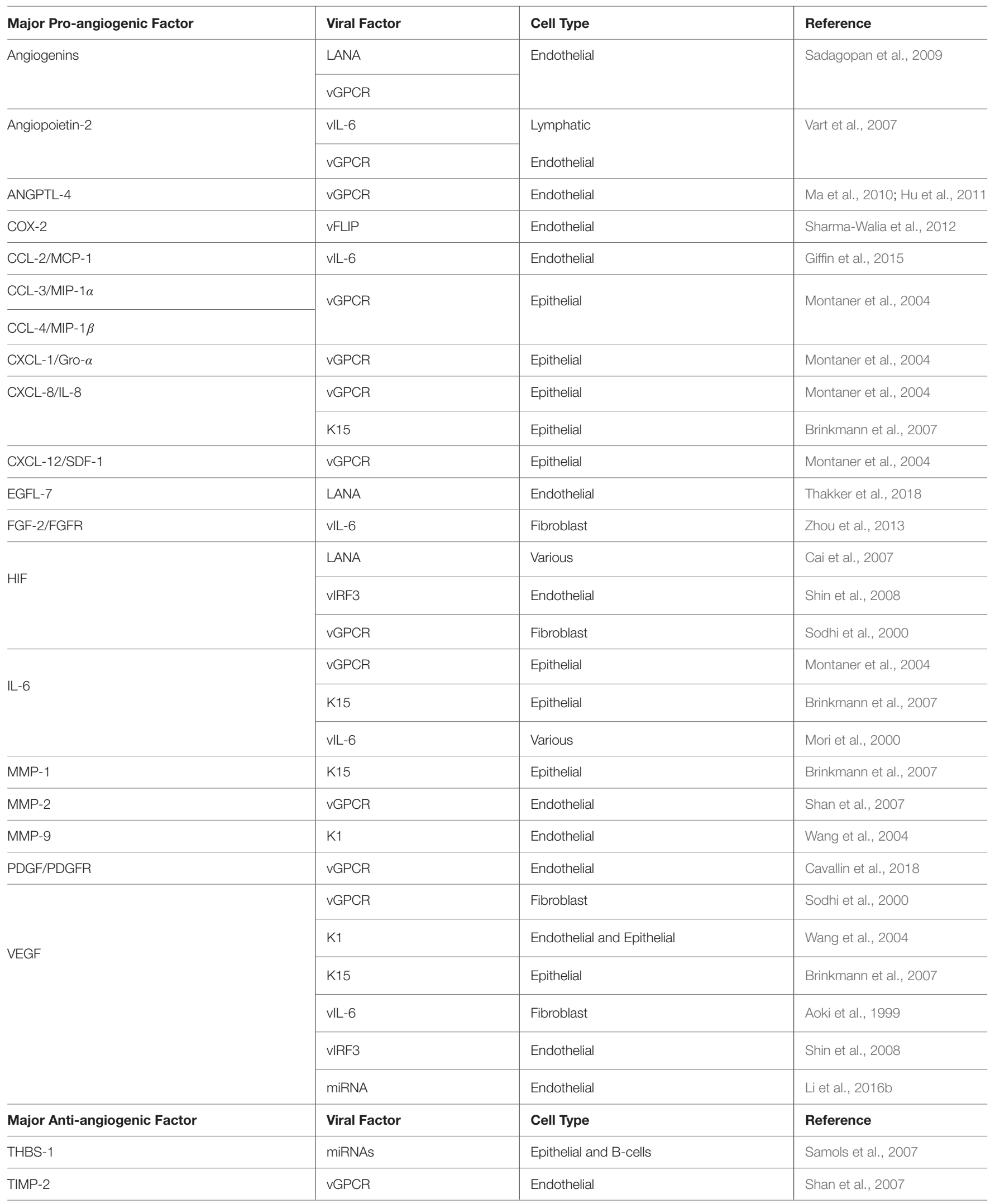




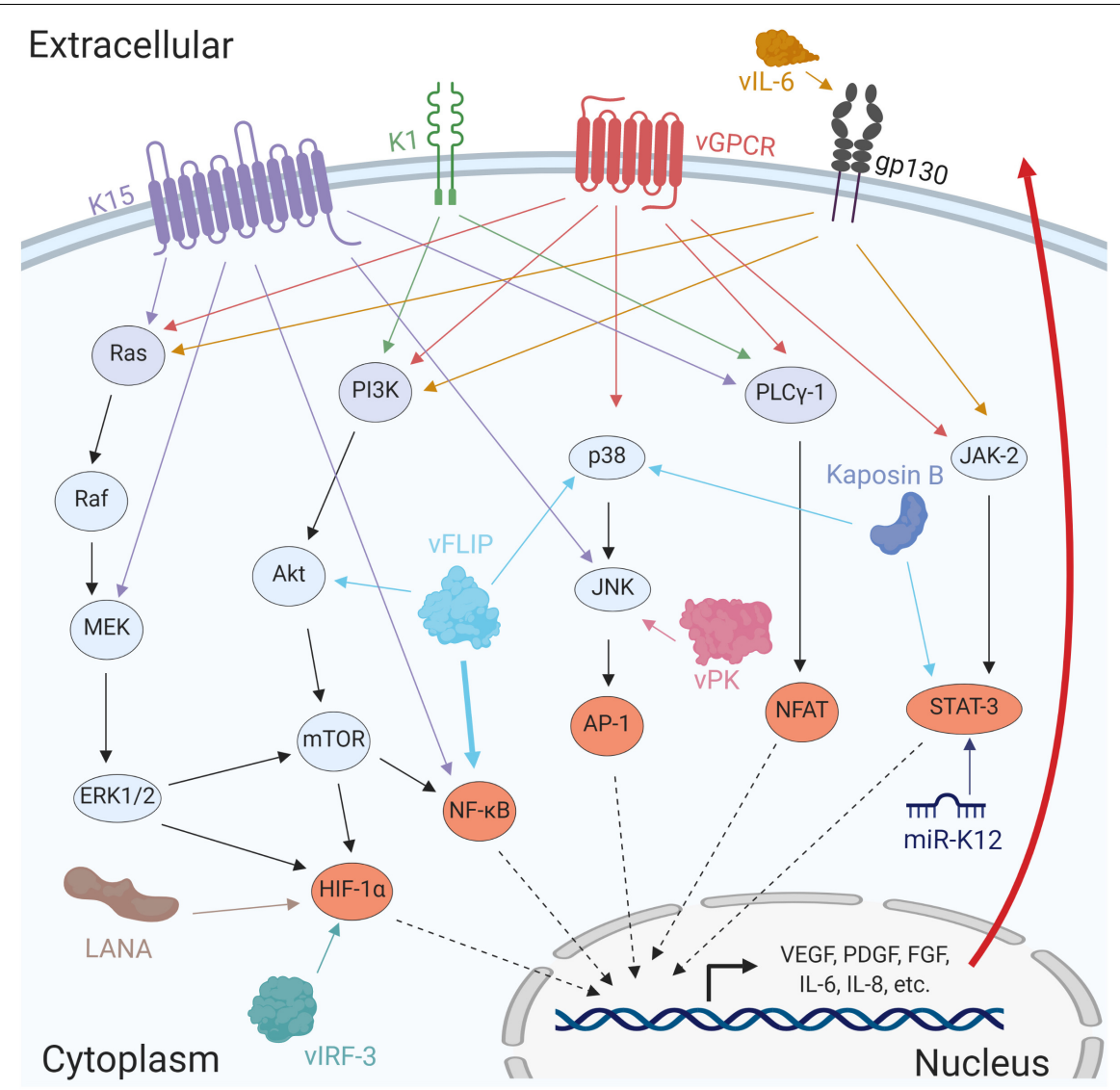

FIGURE 4 | Several KSHV proteins and miRNAs promote angiogenesis by activating cellular signaling pathways. The viral factors LANA, vFLIP, Kaposin B, vIRF-3, and the miRNAs miR-K12 induces activation of major transcription factors such as HIF-1 $\alpha, N F-\kappa B$, AP-1, and STAT-3. Additionally, the viral proteins K1, K15, vGPCR, VIL-6, and vPK cooperate in the activation of multiple signaling pathways promoting expression of angiogenic factors resulting in stronger viral tumorigenesis.

The ability of KSHV to infect a variety of cells, including endothelial and B-cells, is the starting point for a strong induction of angiogenic events facilitating tumor growth. As endothelial cells are the major components of blood vessels, manipulation and transformation of these cells is predicted to enhance viral tumorigenicity by, in part, promoting angiogenesis. Endothelial cells express several KSHV entry receptors including, integrins, $\mathrm{xCT}$, and the tyrosine kinase receptor EphrinA2 (EphA2; reviewed in Kumar and Chandran, 2016). Viral binding to these receptors leads to the formation of signaling complexes promoting the interaction with $\mathrm{PI} 3 \mathrm{~K}, \mathrm{FAK}, \mathrm{Src}$, and $\mathrm{c}-\mathrm{Cbl}$, thereby activating these signaling pathways (Chakraborty et al., 2012; Dutta et al., 2013). This process does not only allow for viral entry, but it is also predicted to modulate pro-angiogenic signaling as EphA2 is known to crosstalk with VEGF signaling (Barquilla and Pasquale, 2015).

In just a couple of decades, researchers have identified several viral factors, expressed during both latent and lytic cycles, that are involved in modulating angiogenesis and may represent viable targets against KSHV-associated malignancies. Next, we will review the current knowledge of how individual genes contribute to the angiogenic process.

\section{Latency-Associated Nuclear Antigen}

The latency-associated nuclear antigen (LANA), encoded by ORF73 and homologous to EBNA1, is a major latency protein that tethers the KSHV episome to the host genome, allowing viral replication during regular cellular division (reviewed in Weidner-Glunde et al., 2017). LANA utilizes several mechanisms to promote angiogenesis, including inhibiting tumor suppressors and miRNAs to promote activation of transcription factors that modulate pro-angiogenic proteins.

The LANA-mediated inhibition of the VHL and p53 tumor suppressors promotes the stabilization of HIF-1 $\alpha$ (Cai et al., 2006, 2007). LANA also stabilizes the Notch effector Hey-1, preventing its degradation, and facilitating Notch signaling (Wang et al., 2014). Furthermore, LANA sequesters death-associated protein 6 (Daxx), allowing Ets-1 to modulate the expression of the proangiogenic factors VEGFR-1, VEGFR-2, and epidermal growth factor-like domain 7 (EGFL-7; Murakami et al., 2006; Thakker et al., 2018). Another mechanism by which LANA enhances the expression of the transcription factors Ets-1 and Ets-2 is repression of cellular miRNAs miR-221 and miR-222 (Wu et al., 2011). This process contributes to the expression of proangiogenic genes. 
Moreover, LANA increases the expression and secretion of Ang-2 and the extracellular matrix metalloproteinase inducer (EMMPRIN; also known as CD147), which promotes invasiveness by activating signaling pathways such as PI3K/Akt and MAPK/ERK (Sadagopan et al., 2009; Qin et al., 2010; Dai et al., 2012). In KSHV-infected endothelial cells, EMMPRIN also induces the metalloproteinases ADAMTS-1 (a disintegrin and metalloproteinase with thrombospondin motifs) and ADAMTS-9, and the pro-angiogenic protein heme-oxygenase (HO) 1 (Dai et al., 2016a,b). To conclude, LANA plays at least two essential roles in KSHV-infected cells: ensuring the maintenance of latency and promoting viral tumorigenesis in part by inducing angiogenesis.

\section{vFLIP and vCyclin}

ORF71 and ORF72 are expressed together as they are located in a bicistronic mRNA and code for the viral FLICE (FADD-like interferon converting enzyme)-like inhibitory protein (vFLIP) and the cyclin D homolog, vCyclin, respectively (Dittmer et al., 1998). Both genes are expressed during latency, and their proteins modulate pro-survival and cell proliferation pathways. Introduction of vFLIP in endothelial cells modulates the expression of a number of genes that are essential for blood vessel development (Punj et al., 2009). Importantly, vFLIP can directly interact with IкB kinase (IKK) $\alpha$, IKK $\beta$, and IKK $\gamma /$ NF$\kappa B$ essential modulator (NEMO) complexes, promoting ІкB $\alpha$ destruction and thus NF- $\mathrm{KB}$ activation (Field et al., 2003; Guasparri et al., 2004). Additionally, it was recently demonstrated that vFLIP uses an alternative pathway to induce the activation of NF- $\kappa \mathrm{B}$ by promoting the degradation of the histone deacetylase complex components SAP-18 and histone deacetylase (HDAC) 1, which target p65 for deacetylation (Ding et al., 2019). Importantly, activation of NF- $\mathrm{KB}$ is essential for vFLIP-induced endothelial cell migration, invasion, and angiogenesis (Ding et al., 2019). In an NF-kB-dependent manner, and in coordination with LANA, vFLIP increases expression of the epigenetic modifier $\mathrm{EZH} 2$, which in turn modulates the pro-angiogenic factor Ephrin-B2 (He et al., 2012).

Furthermore, in endothelial cells, vFLIP plays an essential role in KSHV-induced expression and secretion of COX-2 and PGE2 (Sharma-Walia et al., 2006, 2010; George Paul et al., 2010). This induction of COX-2 not only requires NF- $\mathrm{\kappa B}$ but is also dependent on PI3K/Akt and p38/MAPK (Sharma-Walia et al., 2012). Finally, both vFLIP and vCyclin can induce expression of the host microRNA cluster miR-17/92, which targets Smad2 and perturbs TGF- $\beta$ signaling (Choi H. S. et al., 2015). This process is hypothesized to modulate viral-induced angiogenesis as, paradoxically, TGF- $\beta$ has both pro- and anti-angiogenic functions (Principe et al., 2014). Although not much is known about the role of vCyclin in angiogenesis, these studies have demonstrated that mostly through the activation of NF- $\mathrm{KB}$, vFLIP is important for KSHV-induced angiogenesis.

\section{Kaposins}

The ORF K14 encodes Kaposin A, while Kaposins B and C transcription begins upstream of ORF K14. Kaposins A and $\mathrm{C}$ have not been thoroughly studied, although it has been shown that Kaposin A has oncogenic potential as it can induce focus formation in Rat-3 and NIH3T3 cells and form tumors in nude mice (Kliche et al., 2001; Chen X. et al., 2009). Additionally, the expression of Kaposin B results in the activation of pro-inflammatory and pro-angiogenic signaling involving p38/MK-2 and STAT-3 (McCormick and Ganem, 2005; King, 2013). Importantly, activation of p38/MK2 promotes the accumulation of AU-rich element-containing mRNAs, including prospero homeobox protein 1 (PROX1; Yoo et al., 2010). Consequently, this process allows for the stabilization of PROX-1 mRNA, which contributes to KSHV-induced lymphatic reprogramming of blood endothelial cells (Hong et al., 2004). Another mechanism by which Kaposin B modulates angiogenesis involves inactivation of the host miRNAs miR-221 and miR-222 in a c-Myc-dependent manner (Chang et al., 2016). As mentioned above, these two miRNAs target the transcription factors Ets-1 and Ets-2. To conclude, these studies highlight the roles of the Kaposins in mediating viral-induced pathogenesis and possibly contributing to tumor angiogenesis.

\section{KSHV MicroRNAs}

Kaposi's sarcoma-associated herpesvirus encodes 12 precursor microRNAs that are processed into at least 25 mature miRNAs that target viral and host mRNAs to maintain latency while also promoting tumorigenesis (Cai et al., 2005; Pfeffer et al., 2005; Samols et al., 2005). These miRNAs are expressed during latency and are abundant in KSHV-associated malignancies (Marshall et al., 2007; O’Hara et al., 2009a,b). In order to promote angiogenesis, several miRNAs target cellular anti-angiogenic and anti-proliferative proteins such as THBS-1 (Samols et al., 2007; Gallaher et al., 2013). KS tumor tissues show low levels of THBS1 , and several miRNAs have been identified to target its transcript, resulting in a reduction in TGF- $\beta$ activity (Taraboletti et al., 1999; Samols et al., 2007).

Moreover, the KSHV miRNA K12-6-5p targets the breakpoint cluster region, enhancing Rac-1 activity, and promoting tubule formation (Ramalingam et al., 2015). Rac-1 belongs to the Rho family of GTPases involved in angiogenesis and reorganization of the cytoskeleton. Additionally, miRNA K12-6-5p targets the metastasis suppressor CD82, allowing c-Met to be activated, and induces endothelial cell invasion and angiogenesis ( $\mathrm{Li}$ et al., 2017). In addition to the viral proteins known to activate the PI3K/Akt pathway (Bhatt and Damania, 2012), KSHV miR-K12-3 targets G protein-coupled receptor kinase 2 (GRK-2), promoting the activation of CXCR-2/Akt (Li et al., 2016a). This increase in Akt activity enhances the invasiveness and angiogenic potential of endothelial cells ( $\mathrm{Li}$ et al., 2016a). Furthermore, KSHV miRNAs modulate the activation of the JAK/STAT signaling pathway. For example, expression of miR-K12-6-3p promotes the degradation of SH3 domain-binding glutamic acid-rich protein (SH3BGR), relieving STAT-3 repression and allowing nuclear translocation and expression of pro-angiogenic genes such as MMP-13, VEGFA, and VEGFR-2 (Li et al., 2016b). Together, these studies illustrate the mechanisms that a handful of viral miRNAs utilize to promote tumorigenesis. 


\section{K1}

The ORF K1 is located on the extreme left end of the KSHV genome (reviewed in Sousa-Squiavinato et al., 2015). It is an immunoreceptor tyrosine-based activation motif (ITAM)containing transmembrane glycoprotein with transforming capacities, able to immortalize endothelial cells (Lee et al., 1998; Wang et al., 2006). Through its ITAM, K1 recruits SH2-containing proteins such as Syk and phosphoinositide phospholipase C (PLC) $\gamma-1$ and induces their constitutive activation (Figure 4; Lagunoff et al., 1999; Lee et al., 2005). Expression of $\mathrm{K} 1$ in endothelial cells leads to an increase in activation of the PI3K/Akt pathway, resulting in the secretion of VEGF and consequently angiogenic activity (Tomlinson and Damania, 2004; Wang et al., 2004). Additionally, K1 can synergize with the HIV protein Nef to induce the expression of cellular miR-718, which targets PTEN and thus promotes the activation of the PI3K/Akt pathway, inducing angiogenesis in both in vitro and in vivo models (Xue et al., 2014). Similarly, through the modulation of another cellular miRNA, miR-891a-5p, K1 synergizes with HIV-1 Tat to promote angiogenic processes by activating NF- $\mathrm{KB}$ signaling (Yao et al., 2015). Thus, K1 activation of several signaling pathways, chiefly PI3K/Akt, promotes the angiogenic activity of endothelial cells.

\section{K15}

Located at the right end of the viral genome, ORF K15 encodes a transmembrane protein composed of eight alternatively spliced exons (Choi et al., 2000). K15 is a functional homolog to EBV's LMP2A, and its expression modulates pro-angiogenic cytokines and chemokines such as IL-6, IL8, and CCL-20 (Brinkmann et al., 2007; Bala et al., 2012). The cytoplasmic tail of K15 contains SH2- and SH3-binding motifs that recruit and constitutively activate PLC $\gamma-1$ (Glenn et al., 1999). Moreover, K15 activates signaling pathways involving Ras, JNK, NF- $\mathrm{KB}$ and the transcription factors AP1 and nuclear factor of activated T-cells (NFAT) (Figure 4; Brinkmann et al., 2003; Cho et al., 2008). Recruitment of PLC $\gamma-1$ and activation of NFAT are essential for K15 to induce pro-angiogenic phenotypes such as endothelial cell tubule formation (Bala et al., 2012; Gramolelli et al., 2015). This angiogenic process involves the expression of regulator of calcineurin (RCAN) 1, which is induced explicitly by K15 via activation of calcineurin (Bala et al., 2012). In sum, several studies have suggested that most of the proangiogenic signaling induced by $\mathrm{K} 15$ is mediated through the activation of NFAT.

\section{Viral Interleukin-6}

The ORF K2 encodes viral interleukin-6 (vIL-6), and its expression can be detected at low levels during latency but increases upon lytic replication. As the name indicates, vIL-6 is the viral homolog of human IL-6, and they share some properties such as the ability to induce activation of the JAK/STAT signaling pathway (Moore et al., 1996; Molden et al., 1997; Neipel et al., 1997; Nicholas et al., 1997; Chen D. et al., 2009).
However, in contrast to hIL-6, which requires both parts of the IL-6 receptor (IL-6R; gp80 and gp130), vIL-6 can induce signaling through gp130 in the absence of IL-6R $\alpha$ (gp80). This allows the viral protein to constitutively activate the pathway promoting cell proliferation, migration, and angiogenesis (Aoki et al., 1999; Chen D. et al., 2009; Giffin et al., 2014, 2015; $\mathrm{Wu}$ et al., 2014). The involvement of vIL-6 in mediating angiogenesis was demonstrated when vIL-6-expressing NIH3T3 cells formed highly vascularized tumors in nude mice (Aoki et al., 1999). vIL-6 is an important player in the pathogenesis of Multicentric Castleman's disease (MCD), as the viral cytokine can be detected in the serum of patients, induce MCD-like disease in mice, and promote secretion of hIL-6, a significant contributor to the disease (Mori et al., 2000; Aoki et al., 2001; Suthaus et al., 2012).

vIL-6 is sufficient, but not necessary, for KSHV-induced differentiation of blood to lymphatic endothelial cells (Morris et al., 2012). Importantly, the induction of the lymphatic markers PROX-1, VEGFR-3, and podoplanin (PDPN), expressed in KS tumor cells, requires the activation of both JAK/STAT and PI3K/Akt pathways (Morris et al., 2012). Moreover, in addition to the KSHV proteins mentioned above, vIL-6 also represses TGF- $\beta 2$ signaling to levels seen with KSHV infection (DiMaio et al., 2014). The suppression of TGF- $\beta 2$ is essential for viral-induced tubule formation (DiMaio et al., 2014). Similar to K1, vIL-6 has been found to synergize with HIV-1 proteins Tat and Nef to promote angiogenesis through activation of the PI3K/Akt pathway (Zhou et al., 2013; Zhu et al., 2014). vIL-6 is also involved in promoting endothelial cell migration, and possible angiogenesis, by activating proteins such as carcinoembryonic antigen-related adhesion molecule (CECAM) 1, hypoxia-upregulated protein (HYOU) 1, DNA methyltransferase (DNMT) 1, and CCL-2 (Giffin et al., 2014, 2015; Wu et al., 2014). In conclusion, a multitude of studies using both in vitro and in vivo models have demonstrated the highly pro-angiogenic functions of vIL-6 and how this viral protein might contribute to KSHV-associated malignancies.

\section{Viral G-Protein Coupled Receptor}

ORF74 encodes the early lytic protein viral G-protein coupled receptor (vGPCR), the viral homolog to cellular CXCR-1 (Cesarman et al., 1996; Arvanitakis et al., 1997). Activation of the IL-8 receptor CXCR-1 is widely known to be pro-angiogenic in endothelial cells (Figure 2; Li et al., 2003). vGPCR activates major signaling pathways including p38, JNK, PI3K/Akt, MEK/ERK, JAK/STAT, and Wnt $/ \beta$-cat, and the transcription factors AP1, CREB, NFAT and NF-кB (Figure 4; Bais et al., 1998; Sodhi et al., 2000; Cannon et al., 2003; Burger et al., 2005; Angelova et al., 2014; Wong and Damania, 2017). Activation of these signaling pathways leads to the vGPCR-mediated secretion of pro-angiogenic factors such as IL-6, IL-8, GRO$\alpha$, CCL-3, CCL-4, stromal cell-derived factor 1 (SDF-1 $\beta$ ), and VEGF (Montaner et al., 2004). In contrast to VEGF, whose expression is mainly dependent on HIF- $1 \alpha$, secretion of the other cytokines is dependent on the GTPase Rac-1 (Sodhi et al., 2000; Schwarz and Murphy, 2001; Montaner et al., 2004). 
In addition to the above-mentioned signaling pathways, the Hippo pathway has recently been highlighted as an important contributor to angiogenesis (Kim et al., 2017; Boopathy and Hong, 2019). vGPCR activates the downstream mediators of the Hippo pathway, Yes-associated proteins (YAP)/Tafazzin (TAZ), which in turn may facilitate the angiogenic process by mediating VEGFR signaling and expression of angiopoietin-2 (Choi H. J. et al., 2015; Liu et al., 2015).

Viral G-protein coupled receptor immortalizes HUVECs and induces the expression of VEGFR-2, which is vital for the survival of these cells (Montaner et al., 2001; Bais et al., 2003). Furthermore, vGPCR transforms NIH3T3 cells and promotes the formation of highly vascularized tumors in nude mice (Bais et al., 1998). Secreted factors from vGPCR-expressing cells, especially VEGF, induce tubule formation in endothelial cells, suggesting the involvement of paracrine signaling in promoting angiogenesis (Bais et al., 2003). Finally, conditioned media from vGPCR-expressing cells induce the expression in HUVECs of pyruvate kinase 2 (PKM-2), which acts as a coactivator of HIF-1 to promote aerobic glycolysis and tubule formation (Ma et al., 2015).

As a potent inducer of angiogenic processes, vGPCR modulates the expression of other pro-angiogenic proteins such as Ang-2, which is necessary for the survival of KSHVinfected endothelial cells, and angiopoietin-like (ANGPTL) 4, which promotes angiogenesis and vascular permeability in endothelial cells (Sadagopan et al., 2009; Ma et al., 2010; $\mathrm{Hu}$ et al., 2011). Additionally, in coordination with vIL-6 and dependent on MEK/ERK signaling, vGPCR induces the expression of angiopoietin-2 in lymphatic endothelial cells (Vart et al., 2007). Furthermore, through activation of Src, vGPCR induces membrane type (MT) 1-MMPs and represses TIMP-2, resulting in an increase of MMP-2 and arterial endothelial-cell tubule formation (Shan et al., 2007). Taken together, these studies demonstrate that vGPCR is a potent inducer of pro-angiogenic processes, and thus, it is expected to contribute significantly to KSHV-associated malignancies.

\section{Viral Interferon Regulatory Factors}

Kaposi's sarcoma-associated herpesvirus encodes four viral homologs to cellular interferon regulatory factors (IRFs) (reviewed in Jacobs and Damania, 2011). They play an essential role in inhibiting their cellular counterparts' innate function. Although it is likely that all four vIRFs contribute to the pathogenesis of KSHV, especially by modulating Notch and TGF$\beta /$ Smad signaling, only vIRF3 has been identified to have a role in promoting angiogenesis (Jacobs and Damania, 2011). vIRF-3, also known as LANA-2, is a latently expressed protein that interacts with HIF-1 $\alpha$, promoting its stabilization and pro-angiogenic signaling including the expression of VEGF (Figure 4; Rivas et al., 2001; Shin et al., 2008). Furthermore, vIRF-3 can also interact with HDAC-5, sequestering it in the nucleus, and inducing expression of the lymphatic markers PDPN and PROX-1 (Lee et al., 2018). These markers, which are also induced in KSHV-infected endothelial cells, contribute to the spindle-shape form characteristic of KS (Lee et al., 2018). Finally, vIRF-3 is necessary for KSHV-induced lymphatic endothelial cell tubule formation and sprouting (Lee et al., 2018). Thus, in addition, to playing a role in repressing host antiviral response, vIRFs may contribute to KSHVinduced angiogenesis.

\section{Viral CC Chemokine Ligands}

Kaposi's sarcoma-associated herpesvirus encodes three CC chemokine ligands (CCLs), vCCL-1 (ORF K6), vCCL-2 (ORF K4), and vCCL-3 (ORF K4.1; Nicholas et al., 1997). These were previously known as viral macrophage inhibitory proteins (vMIPs). These viral proteins can interact with cellular CC-chemokine receptors and inhibit their signaling. All three vCCLs have been found to induce pro-angiogenic phenotypes in both in vitro and in vivo models (Boshoff et al., 1997; Stine et al., 2000; Cherqui et al., 2007). In particular, vCCL2 has been identified as capable of binding to multiple chemokine receptors, thus able to act on several cell types (Szpakowska and Chevigne, 2016). Therefore, vCCLs may play an essential role in the tumor microenvironment not only by acting on virus-infected cells but also by recruiting immune cells.

\section{Viral Protein Kinase}

The viral protein kinase (vPK) encoded by ORF36 is one of two kinases expressed by KSHV (Park et al., 2000). The other kinase is the homolog of cellular thymidine kinase encoded by ORF21. The expression of $\mathrm{vPK}$ is detected mostly during lytic replication, although it can also be detected in the absence of full lytic replication. This expression during latency is hypothesized to occur during hypoxic conditions as HIF proteins upregulate vPK expression via HIF response elements located at the promoter of the ORF34-37 cluster (Haque et al., 2006). Notably, vPK activates the JNK pathway by phosphorylating mitogen-activated protein kinase kinase (MKK)-4 and MKK-7 (Hamza et al., 2004).

Furthermore, vPK mimics the activity of the cellular protein S6 kinase $\beta 1$ (P70S6K1), promoting protein synthesis by activating ribosomal protein $\mathrm{S} 6$ and eukaryotic initiation factor 4B (EIF4B; Bhatt et al., 2016). Both S6 and EIF4B are downstream components of the PI3K/Akt pathway that promote translation of HIF-1 $\alpha$, enhancing angiogenesis (Karar and Maity, 2011). Importantly, expression of vPK augments anchorage-independent growth and promotes endothelial cell tubule formation (Bhatt et al., 2016). In addition to its oncogenicity in vitro, vPK expressed in transgenic mice generates a hyperproliferation of B-cells and a higher incidence of B-cell non-Hodgkin's lymphomas (Anders et al., 2018). Together, these studies demonstrate a tumorigenic role for this viral kinase and its possible involvement in promoting angiogenesis.

\section{IN VIVO MODELS TO STUDY EBV- AND KSHV-INDUCED ANGIOGENESIS}

The lack of tropism for murine cells by both EBV and KSHV has required the development of methods to study 
viral-induced malignancies in vivo. Most in vivo studies rely on the engraftment of tumor or viral protein-expressing cells into mice, or transgenic mice expressing the viral proteins. Another approach to study the viruses in vivo involves the humanization of the mice, which makes the animal permissive for viral infection. These studies have proven to be useful for the characterization of viral proteins and RNAs, especially in the context of lymphomagenesis. Several recent reviews published elsewhere had discussed these in vivo models in detail (Dittmer et al., 2015; Fujiwara et al., 2015; Ahmed and Baiocchi, 2016; Purushothaman et al., 2016; Munz, 2017; Fujiwara, 2018; Bravo Cruz and Damania, 2019).

Transgenic mice expressing viral proteins such as KSHV vGPCR demonstrates the involvement of this protein in inducing highly angiogenic KS-like lesions (Holst et al., 2001; Guo et al., 2003). Furthermore, conditional transgenic mice have also been created, allowing for the doxycycline-inducible expression of viral genes (Jensen et al., 2005; Grisotto et al., 2006). To restrict the expression to specific cell types, such as endothelial cells, the Tie2-tva transgenic mice was developed. This mouse model expresses the avian leukosis virus (ALV) receptor, Tva, under a Tie2 promoter restricting the expression of the receptor to endothelial cells (Montaner et al., 2003). These cells are permissive to infection with ALV-derived retroviruses expressing a viral gene of interest. Similar to the previous model, expression of vGPCR in these cells also led to the formation of highly angiogenic KS-like lesions (Montaner et al., 2003; Sodhi et al., 2004, 2006).

The models to study EBV-induced angiogenesis in vivo have not been developed to the same extent as with KSHV. Most of these models consist of the injection of EBV-positive NPC cells or EBV-transformed LCLs into immunocompromised mice (Hong et al., 2005b; Smith et al., 2011; Yang et al., 2015; Ma et al., 2018; Ye et al., 2018). Although these models have not been extensively used for angiogenic studies, they have provided vital knowledge with regards to protumorigenic viral factors.

Two cell lines used for in vitro and also in vivo studies are the telomerase-immortalized vein endothelial (TIVE) cells or the BAC36-transfected murine cells (mECK36), which are suitable models due to their ability to grow and resemble KS in vivo (An et al., 2006; Mutlu et al., 2007). These models allow for the characterization of essential cellular and viral factors that contribute to tumorigenesis and also for the testing of possible therapeutic compounds. For studying PEL, several cell lines, notably BCBL-1, injected into immunocompromised mice give rise to tumors. Even though this model induces the formation of a solid tumor, cells produce an accumulation of ascites resembling PEL and allowing for the studies of anti-tumorigenic compounds. Furthermore, patient-derived xenografts were recently established to study NPC (Lin et al., 2018). Altogether, these technological advances have provided suitable tools to study viral-induced malignancies in animals.

The chicken chorioallantoic membrane (CAM) assay has been widely used to study angiogenesis in vivo. This assay is simplistic due to the nature of the highly vascularized extraembryonic membrane following the fertilization of the egg (Nowak-Sliwinska et al., 2014). Cells, proteins, or compounds can be incorporated into the membrane allowing for the assessment of the effect of these factors in mediating angiogenesis. The whole embryo can be removed from the eggshell and placed on a petri dish to facilitate the imaging process. In fact, this method has been used by several groups to demonstrate KSHV-induced angiogenesis (Stine et al., 2000; Zhou et al., 2013; Zhu et al., 2014). Thus, the CAM assay provides a cost-effective approach to study angiogenesis in an in vivo context.

\section{TARGETING ANGIOGENESIS IN EBV- AND KSHV-ASSOCIATED MALIGNANCIES}

Research into EBV- and KSHV-induced angiogenesis has suggested an essential role for this process in viral tumorigenesis. As discussed above, virus infection or expression of viral proteins and non-coding RNAs have already been identified as contributing to this process. These studies have paved the way for several clinical trials of compounds with anti-angiogenic activity to treat viral malignancies, particularly KS and NPC.

Since the mid-2000s, several inhibitors with anti-angiogenic activity, including chemical and biological agents, have been clinically approved for different types of cancers (Ribeiro et al., 2018). These include the VEGF inhibitor bevacizumab (Avastin), VEGFR-2 antagonist ramucirumab (Cyramza) and several receptor tyrosine kinase (RTK) inhibitors that target VEGFRs, c-Met, and PDGFR, such as sunitinib (Sutent) and cabozantinib (Cabometyx). Also, the immunomodulatory compounds thalidomide (Immunoprin) and lenalidomide (Revlimid) used to treat multiple myeloma show anti-angiogenic activity by targeting angiogenic inducers such as IL-6, NF- $\mathrm{B}, \mathrm{COX}-2$, and VEGF (Ribeiro et al., 2018).

Several of these inhibitors have been tested or are currently undergoing clinical trials against EBV- and KSHV-associated malignancies. For example, the switch of immunosuppressant from cyclosporin A to the mTOR inhibitor rapamycin (Sirolimus) elicited KS regression in transplant patients, and it is now the first line of treatment for transplant KS (Stallone et al., 2005). The PI3K/Akt/mTOR pathway has proven to be vital for KS and PEL, and several inhibitors have proven to be efficacious in pre-clinical studies (Sin et al., 2007; Bhatt et al., 2010; Roy et al., 2013). Furthermore, Uldrick et al. (2012) reported that out of $16 \mathrm{KS}$ patients treated with bevacizumab, 31\% showed complete or partial response. However, in another small group of patients, although well tolerated, intralesional administration of bevacizumab had no significant effect against upper respiratory tract KS (Ablanedo-Terrazas et al., 2015). Thus, targeting VEGF with bevacizumab has a moderate effect against KS.

Additionally, targeting the receptor tyrosine kinases, c-kit, and PDGFR, with the inhibitor imatinib (Gleevec), provided a long-term benefit to a third of patients suffering from the most aggressive KS subtype, AIDS-KS (Koon et al., 2014). Moreover, 16 of $22 \mathrm{KS}$ patients that were treated with pomalidomide responded well and rapidly to the treatment (Polizzotto et al., 2016). 
Additionally, several of these immunomodulatory compounds that show anti-tumorigenic and anti-angiogenic activity are currently being studied for treatment against KSHV- and EBVassociated lymphomas (NCT02911142). Furthermore, the antiIL-6 antibody siltuximab (Sylvant) has been FDA approved for idiopathic MCD, and the anti-IL-6R (gp80) antibody tocilizumab (Actemra) is currently been tested in KSHV-associated MCD patients (NCT01441063; van Rhee et al., 2014).

In NPC patients, the addition of bevacizumab to standard chemoradiation proved to be safe and suggested that the treatment might delay the progression of the disease (Lee et al., 2012). Furthermore, the combination of the recombinant endostatin (Endostar), which inhibits VEGF, with gemcitabine and cisplatin increased the overall survival of metastaticNPC patients (Jin et al., 2018). In contrast, the use of the EGFR inhibitor erlotinib (Tarceva) as maintenance following gemcitabine plus platinum-based chemotherapy was ineffective in recurrent or metastatic NPC patients (You et al., 2012). Thus, the addition of these anti-angiogenic compounds in combination with standard chemotherapy may become a standard treatment for NPC patients.

Importantly, apart from the anti-VEGF therapies, most of these therapeutics were not developed as anti-angiogenic. Nevertheless, their effect in reducing angiogenesis is predicted to be a product of inhibiting pathways known to contribute to angiogenic processes. Thus, these clinical studies have highlighted the potential benefit of several different therapeutic approaches that may contribute to reducing pro-angiogenic mechanisms. Consequently, more studies are currently underway and as new anti-angiogenic therapeutic approaches are developed, we can expect that patients suffering from EBVand KSHV-associated malignancies will eventually benefit from these treatments.

\section{CONCLUDING REMARKS AND FUTURE PERSPECTIVES}

Angiogenesis is one of the hallmarks of cancer, and the ability of a tumor to hijack this process for its benefit facilitates growth and enhances its ability to metastasize (Hanahan and Weinberg, 2011). Viral cancers are not an exception (Mesri et al., 2014). Two of the seven known human oncoviruses, EBV and KSHV, belong to the Gammaherpesvirinae subfamily. Both viruses are linked to several malignancies, including both solid and liquid tumors. Importantly, both viruses are known to have pro-angiogenic activity that enhances their tumorigenesis.

Most of the research into EBV- and KSHV-induced angiogenesis has been accomplished just in the last two decades. However, several viral factors, especially in KSHV, have already been identified as playing a direct and substantial role in modulating pro-angiogenic processes, leading to clinical trials using anti-angiogenic inhibitors. The fact that the induction of angiogenesis is not restricted to a single viral factor suggests the importance of this process in mediating viral pathogenesis. Specifically, both latent and lytic proteins are involved in this process, supporting the hypothesis that paracrine signaling is vital for these viral-induced malignancies. In KSHV-associated malignancies, the current knowledge points to lytic proteins such as vGPCR and vIL-6 to be amongst the most potent pro-angiogenic inducers. However, in the context of EBV tumorigenesis, the latent protein LMP1, appears to be the major pro-angiogenic factor. Interestingly, EBV encodes a constitutively active GPCR known as BILF1 that has not been exhaustively studied, although it is known that it can induce tumors in nude mice (Paulsen et al., 2005; Lyngaa et al., 2010). It would be of significant interest to determine whether BILF1 contributes to EBV-induced angiogenesis.

The emerging field of non-coding RNAs, which includes both cellular and viral miRNAs, long non-coding (lnc) RNAs, and circular (circ) RNAs, may be significant contributors to angiogenesis (Khorshidi et al., 2016). As discussed above, EBV and KSHV express miRNAs that have been demonstrated to be involved in mediating angiogenesis. Recently, a few cellular lncRNAs have been identified to be regulated during hypoxia and contributing to tumor angiogenesis (Yu and Wang, 2018). Additionally, circRNAs may also be important players in regulating this pathological process (Su et al., 2019). As both viruses, EBV and KSHV, express these types of non-coding RNAs, it would be of significant interest to determine whether, in addition to miRNAs, the other non-coding RNAs contribute to viral-induced angiogenesis (Tagawa et al., 2018; Toptan et al., 2018; Ungerleider et al., 2018, 2019). Importantly, the development of animal models, including mouse and zebrafish, are promising methods for the in vivo characterization of these non-coding RNAs (Feyder and Goff, 2016).

Furthermore, new techniques to study angiogenesis in vitro are currently being developed. One such tool consists of the "organ-on-chip" technology that allows for the study of vascularized microtumors (VMT) using real-time fluorescence microscopy (Sobrino et al., 2016). This in vitro 3D model may become useful not only for studying the vasculature but also for the screening of compounds with anti-angiogenic potential against viral-induced malignancies. These assays, in coordination with the development of new therapeutics targeting cellular pathways involved in angiogenesis, may provide a positive outlook for patients suffering from EBV- or KSHV-associated malignancies. This is vital given that most clinical trials with anti-angiogenic compounds have only been partially effective, raising the question on why cancers that appear to be highly dependent on angiogenesis such as KS can still be, to some extent, resistant to this type of therapy. A major hypothesis arises from the fact that viral factors induce a multitude of oncogenic processes besides angiogenesis. These include the induction of cell proliferation and inhibition of apoptosis. Thus, targeting multiple cellular pathways or combining inhibitors against both cellular and viral proteins is hypothesized to reduce the development of resistance, which is not uncommon with single-agent treatments. We predict that in the near future, research into EBV- and KSHV-induced angiogenesis will further delineate the mechanisms by which cellular and viral factors cooperate to modulate the pathological process, and thus provide additional treatment targets to improve the patient's quality of life. 


\section{AUTHOR CONTRIBUTIONS}

Both authors wrote and edited this review.

\section{FUNDING}

This work was supported by Public Health Service Grants CA096500 and CA019014. BD is a Leukemia and Lymphoma Society Scholar, and a Burroughs Wellcome Fund

\section{REFERENCES}

Ablanedo-Terrazas, Y., Alvarado-de la Barrera, C., Ormsby, C. E., Ruiz-Cruz, M. and Reyes-Teran, G. (2015). Intralesional bevacizumab in patients with human immunodeficiency virus-associated Kaposi's sarcoma in the upper airway. Laryngoscope 125, E132-E137. doi: 10.1002/lary.24988

Aga, M., Bentz, G. L., Raffa, S., Torrisi, M. R., Kondo, S., Wakisaka, N., et al. (2014). Exosomal HIFlalpha supports invasive potential of nasopharyngeal carcinoma-associated LMP1-positive exosomes. Oncogene 33, 4613-4622. doi: 10.1038/onc. 2014.66

Ahmed, E. H., and Baiocchi, R. A. (2016). Murine models of Epstein-Barr virusassociated Lymphomagenesis. ILAR J. 57, 55-62. doi: 10.1093/ilar/ilv074

An, F. Q., Folarin, H. M., Compitello, N., Roth, J., Gerson, S. L., McCrae, K. R., et al. (2006). Long-term-infected telomerase-immortalized endothelial cells: a model for Kaposi's sarcoma-associated herpesvirus latency in vitro and in vivo. J. Virol. 80, 4833-4846. doi: 10.1128/JVI.80.10.4833-4846.2006

Anders, P. M., Montgomery, N. D., Montgomery, S. A., Bhatt, A. P., Dittmer, D. P., and Damania, B. (2018). Human herpesvirus-encoded kinase induces B cell lymphomas in vivo. J. Clin. Invest. 128, 2519-2534. doi: 10.1172/JCI97053

Angelova, M., Ferris, M., Swan, K. F., McFerrin, H. E., Pridjian, G., Morris, C. A., et al. (2014). Kaposi's sarcoma-associated herpesvirus G-protein coupled receptor activates the canonical Wnt/beta-catenin signaling pathway. Virol. J. 11:218. doi: 10.1186/s12985-014-0218-218

Aoki, Y., Jaffe, E. S., Chang, Y., Jones, K., Teruya-Feldstein, J., Moore, P. S., et al. (1999). Angiogenesis and hematopoiesis induced by Kaposi's sarcomaassociated herpesvirus-encoded interleukin-6. Blood 93, 4034-4043.

Aoki, Y., and Tosato, G. (1999). Role of vascular endothelial growth factor/vascular permeability factor in the pathogenesis of Kaposi's sarcoma-associated herpesvirus-infected primary effusion lymphomas. Blood 94, 4247-4254.

Aoki, Y., Tosato, G., Fonville, T. W., and Pittaluga, S. (2001). Serum viral interleukin-6 in AIDS-related multicentric Castleman disease. Blood 97, 25262527. doi: 10.1182/blood.v97.8.2526

Arvanitakis, L., Geras-Raaka, E., Varma, A., Gershengorn, M. C., and Cesarman, E. (1997). Human herpesvirus KSHV encodes a constitutively active G-proteincoupled receptor linked to cell proliferation. Nature 385, 347-350. doi: 10.1038/ $385347 \mathrm{a} 0$

Azzi, S., Hebda, J. K., and Gavard, J. (2013). Vascular permeability and drug delivery in cancers. Front. Oncol. 3:211. doi: 10.3389/fonc.2013.00211

Baeriswyl, V., and Christofori, G. (2009). The angiogenic switch in carcinogenesis. Semin. Cancer Biol. 19, 329-337. doi: 10.1016/j.semcancer.2009.05.003

Bais, C., Santomasso, B., Coso, O., Arvanitakis, L., Raaka, E. G., Gutkind, J. S., et al. (1998). G-protein-coupled receptor of Kaposi's sarcoma-associated herpesvirus is a viral oncogene and angiogenesis activator. Nature 391, 86-89. doi: 10.1038/ 34193

Bais, C., Van Geelen, A., Eroles, P., Mutlu, A., Chiozzini, C., Dias, S., et al. (2003). Kaposi's sarcoma associated herpesvirus G protein-coupled receptor immortalizes human endothelial cells by activation of the VEGF receptor-2/ KDR. Cancer Cell. 3, 131-143. doi: 10.1016/s1535-6108(03) 00024-2

Bala, K., Bosco, R., Gramolelli, S., Haas, D. A., Kati, S., Pietrek, M., et al. (2012). Kaposi's sarcoma herpesvirus K15 protein contributes to virusinduced angiogenesis by recruiting PLCgammal and activating NFAT1dependent RCAN1 expression. PLoS Pathog. 8:e1002927. doi: 10.1371/journal. ppat. 1002927
Investigator in Infectious Disease. RR-S was supported by NIH Grant GM007092.

\section{ACKNOWLEDGMENTS}

The authors are thankful to the Damania Lab Members, Ariana Bravo-Cruz, Guoxin Ni, and Whitney Tevebaugh for helpful comments and discussions.

Barquilla, A., and Pasquale, E. B. (2015). Eph receptors and ephrins: therapeutic opportunities. Annu. Rev. Pharmacol. Toxicol. 55, 465-487. doi: 10.1146/ annurev-pharmtox-011112-140226

Bergers, G., and Benjamin, L. E. (2003). Tumorigenesis and the angiogenic switch. Nat. Rev. Cancer 3, 401-410. doi: 10.1038/nrc1093

Bhatt, A. P., Bhende, P. M., Sin, S. H., Roy, D., Dittmer, D. P., and Damania, B. (2010). Dual inhibition of PI3K and mTOR inhibits autocrine and paracrine proliferative loops in PI3K/Akt/mTOR-addicted lymphomas. Blood 115, 44554463. doi: 10.1182/blood-2009-10-251082

Bhatt, A. P., and Damania, B. (2012). AKTivation of PI3K/AKT/mTOR signaling pathway by KSHV. Front. Immunol. 3:401. doi: 10.3389/fimmu.2012.00401

Bhatt, A. P., Wong, J. P., Weinberg, M. S., Host, K. M., Giffin, L. C., Buijnink, J., et al. (2016). A viral kinase mimics S6 kinase to enhance cell proliferation. Proc. Natl. Acad. Sci. U.S.A. 113, 7876-7881. doi: 10.1073/pnas.1600587113

Bielenberg, D. R., and Zetter, B. R. (2015). The contribution of Angiogenesis to the process of metastasis. Cancer J. 21, 267-273. doi: 10.1097/PPO. 0000000000000138

Boopathy, G. T. K., and Hong, W. (2019). Role of Hippo Pathway-YAP/TAZ Signaling in Angiogenesis. Front. Cell. Dev. Biol. 7:49. doi: 10.3389/fcell.2019. 00049

Boshoff, C., Endo, Y., Collins, P. D., Takeuchi, Y., Reeves, J. D., Schweickart, V. L., et al. (1997). Angiogenic and HIV-inhibitory functions of KSHV-encoded chemokines. Science 278, 290-294. doi: 10.1126/science.278.5336.290

Bravo Cruz, A. G., and Damania, B. (2019). In vivo models of oncoproteins encoded by Kaposi's sarcoma-associated herpesvirus. J. Virol. 93, e1053-18. doi: 10.1128/JVI.01053-18

Brinkmann, M. M., Glenn, M., Rainbow, L., Kieser, A., Henke-Gendo, C., and Schulz, T. F. (2003). Activation of mitogen-activated protein kinase and NFkappaB pathways by a Kaposi's sarcoma-associated herpesvirus K15 membrane protein. J. Virol. 77, 9346-9358. doi: 10.1128/jvi.77.17.9346-9358.2003

Brinkmann, M. M., Pietrek, M., Dittrich-Breiholz, O., Kracht, M., and Schulz, T. F. (2007). Modulation of host gene expression by the K15 protein of Kaposi's sarcoma-associated herpesvirus. J. Virol. 81, 42-58. doi: 10.1128/JVI.00648-646

Brown, L. F., Tognazzi, K., Dvorak, H. F., and Harrist, T. J. (1996). Strong expression of kinase insert domain-containing receptor, a vascular permeability factor/vascular endothelial growth factor receptor in AIDS-associated Kaposi's sarcoma and cutaneous angiosarcoma. Am. J. Pathol. 148, 1065-1074.

Buettner, M., Meyer, B., Schreck, S., and Niedobitek, G. (2007). Expression of RANTES and MCP-1 in epithelial cells is regulated via LMP1 and CD40. Int. J. Cancer 121, 2703-2710. doi: 10.1002/ijc.23018

Burger, M., Hartmann, T., Burger, J. A., and Schraufstatter, I. (2005). KSHV-GPCR and CXCR2 transforming capacity and angiogenic responses are mediated through a JAK2-STAT3-dependent pathway. Oncogene 24, 2067-2075. doi: 10. 1038/sj.onc. 1208442

Cai, L., Ye, Y., Jiang, Q., Chen, Y., Lyu, X., Li, J., et al. (2015). Epstein-Barr virusencoded microRNA BART1 induces tumour metastasis by regulating PTENdependent pathways in nasopharyngeal carcinoma. Nat. Commun. 6:7353. doi: $10.1038 /$ ncomms 8353

Cai, Q., Murakami, M., Si, H., and Robertson, E. S. (2007). A potential alpha-helix motif in the amino terminus of LANA encoded by Kaposi's sarcoma-associated herpesvirus is critical for nuclear accumulation of HIF-1alpha in normoxia. J. Virol. 81, 10413-10423. doi: 10.1128/JVI.00611-617

Cai, Q. L., Knight, J. S., Verma, S. C., Zald, P., and Robertson, E. S. (2006). EC5S ubiquitin complex is recruited by KSHV latent antigen LANA for degradation 
of the VHL and p53 tumor suppressors. PLoS Pathog. 2:e116. doi: 10.1371/ journal.ppat. 0020116

Cai, X., Lu, S., Zhang, Z., Gonzalez, C. M., Damania, B., and Cullen, B. R. (2005). Kaposi's sarcoma-associated herpesvirus expresses an array of viral microRNAs in latently infected cells. Proc. Natl. Acad. Sci. U.S.A. 102, 5570-5575. doi: 10.1073/pnas.0408192102

Cannon, M., Philpott, N. J., and Cesarman, E. (2003). The Kaposi's sarcomaassociated herpesvirus $\mathrm{G}$ protein-coupled receptor has broad signaling effects in primary effusion lymphoma cells. J. Virol. 77, 57-67. doi: 10.1128/jvi.77.1. 57-67.2003

Carmeliet, P. (2005). VEGF as a key mediator of angiogenesis in cancer. Oncology 69(Suppl. 3), 4-10. doi: 10.1159/000088478

Carmeliet, P., and Jain, R. K. (2000). Angiogenesis in cancer and other diseases. Nature 407, 249-257. doi: 10.1038/35025220

Carroll, P. A., Kenerson, H. L., Yeung, R. S., and Lagunoff, M. (2006). Latent Kaposi's sarcoma-associated herpesvirus infection of endothelial cells activates hypoxia-induced factors. J. Virol. 80, 10802-10812. doi: 10.1128/JVI.00 673-676

Caselli, E., Benedetti, S., Grigolato, J., Caruso, A., and Di Luca, D. (2012). Activating transcription factor 4 (ATF4) is upregulated by human herpesvirus 8 infection, increases virus replication and promotes proangiogenic properties. Arch. Virol. 157, 63-74. doi: 10.1007/s00705-011-1144-1143

Caselli, E., Fiorentini, S., Amici, C., Di Luca, D., Caruso, A., and Santoro, M. G. (2007). Human herpesvirus 8 acute infection of endothelial cells induces monocyte chemoattractant protein 1-dependent capillary-like structure formation: role of the IKK/NF-kappaB pathway. Blood 109, 2718-2726. doi: 10.1182/blood-2006-03-012500

Cavallin, L. E., Ma, Q., Naipauer, J., Gupta, S., Kurian, M., Locatelli, P., et al. (2018). KSHV-induced ligand mediated activation of PDGF receptor-alpha drives Kaposi's sarcomagenesis. PLoS Pathog. 14:e1007175. doi: 10.1371/journal.ppat. 1007175

Ceccarelli, S., Visco, V., Raffa, S., Wakisaka, N., Pagano, J. S., and Torrisi, M. R. (2007). Epstein-Barr virus latent membrane protein 1 promotes concentration in multivesicular bodies of fibroblast growth factor 2 and its release through exosomes. Int. J. Cancer 121, 1494-1506. doi: 10.1002/ijc. 22844

Cesarman, E., Nador, R. G., Bai, F., Bohenzky, R. A., Russo, J. J., Moore, P. S., et al. (1996). Kaposi's sarcoma-associated herpesvirus contains G protein-coupled receptor and cyclin D homologs which are expressed in Kaposi's sarcoma and malignant lymphoma. J. Virol. 70, 8218-8223.

Chakraborty, S., Veettil, M. V., Bottero, V., and Chandran, B. (2012). Kaposi's sarcoma-associated herpesvirus interacts with EphrinA2 receptor to amplify signaling essential for productive infection. Proc. Natl. Acad. Sci. U.S.A. 109, E1163-E1172. doi: 10.1073/pnas.1119592109

Chandel, N. S., McClintock, D. S., Feliciano, C. E., Wood, T. M., Melendez, J. A., Rodriguez, A. M., et al. (2000). Reactive oxygen species generated at mitochondrial complex III stabilize hypoxia-inducible factor-1alpha during hypoxia: a mechanism of $\mathrm{O} 2$ sensing. J. Biol. Chem. 275, 25130-25138. doi: 10.1074/jbc.M001914200

Chang, H. C., Hsieh, T. H., Lee, Y. W., Tsai, C. F., Tsai, Y. N., Cheng, C. C., et al. (2016). c-Myc and viral cofactor Kaposin B co-operate to elicit angiogenesis through modulating miRNome traits of endothelial cells. BMC Syst. Biol. 10(Suppl. 1):1. doi: 10.1186/s12918-015-0242-243

Chen, D., Sandford, G., and Nicholas, J. (2009). Intracellular signaling mechanisms and activities of human herpesvirus 8 interleukin-6. J. Virol. 83, 722-733. doi: 10.1128/JVI.01517-1518

Chen, X., Cheng, L., Jia, X., Zeng, Y., Yao, S., Lv, Z., et al. (2009). Human immunodeficiency virus type 1 Tat accelerates Kaposi sarcoma-associated herpesvirus Kaposin A-mediated tumorigenesis of transformed fibroblasts in vitro as well as in nude and immunocompetent mice. Neoplasia 11, 12721284. doi: 10.1593/neo.09494

Chen, S. J., Chen, G. H., Chen, Y. H., Liu, C. Y., Chang, K. P., Chang, Y. S., et al. (2010). Characterization of Epstein-Barr virus miRNAome in nasopharyngeal carcinoma by deep sequencing. PLoS One. 5:e012745. doi: 10.1371/journal. pone. 0012745

Cheng, S., Li, Z., He, J., Fu, S., Duan, Y., Zhou, Q., et al. (2019). EpsteinBarr virus noncoding RNAs from the extracellular vesicles of nasopharyngeal carcinoma (NPC) cells promote angiogenesis via TLR3/RIG-I-mediated
VCAM-1 expression. Biochim. Biophys. Acta Mol. Basis Dis. 865, 1201-1213. doi: 10.1016/j.bbadis.2019.01.015

Cherqui, S., Kingdon, K. M., Thorpe, C., Kurian, S. M., and Salomon, D. R. (2007). Lentiviral gene delivery of vMIP-II to transplanted endothelial cells and endothelial progenitors is proangiogenic in vivo. Mol. Ther. 15, 1264-1272. doi: $10.1038 /$ sj.mt. 6300183

Cho, N. H., Choi, Y. K., and Choi, J. K. (2008). Multi-transmembrane protein K15 of Kaposi's sarcoma-associated herpesvirus targets Lyn kinase in the membrane raft and induces NFAT/AP1 activities. Exp. Mol. Med. 40, 565-573. doi: 10.3858/ emm.2008.40.5.565

Choi, H. J., Zhang, H., Park, H., Choi, K. S., Lee, H. W., Agrawal, V., et al. (2015). Yes-associated protein regulates endothelial cell contact-mediated expression of angiopoietin-2. Nat. Commun. 6:6943. doi: 10.1038/ncomms7943

Choi, H. S., Jain, V., Krueger, B., Marshall, V., Kim, C. H., Shisler, J. L., et al. (2015). Kaposi's sarcoma-associated herpesvirus (KSHV) induces the oncogenic miR-17-92 cluster and down-regulates TGF-beta signaling. PLoS Pathog. 11:e1005255. doi: 10.1371/journal.ppat.1005255

Choi, J. K., Lee, B. S., Shim, S. N., Li, M., and Jung, J. U. (2000). Identification of the novel K15 gene at the rightmost end of the Kaposi's sarcoma-associated herpesvirus genome. J. Virol. 74, 436-446. doi: 10.1128/jvi.74.1.436-446.2000

Cohen, M., Vistarop, A. G., Huaman, F., Narbaitz, M., Metrebian, F., De Matteo, E., et al. (2018). Epstein-Barr virus lytic cycle involvement in diffuse large B cell lymphoma. Hematol. Oncol. 36, 98-103. doi: 10.1002/hon.2465

Cornali, E., Zietz, C., Benelli, R., Weninger, W., Masiello, L., Breier, G., et al. (1996). Vascular endothelial growth factor regulates angiogenesis and vascular permeability in Kaposi's sarcoma. Am. J. Pathol. 149, 1851-1869.

Croci, D. O., Salatino, M., Rubinstein, N., Cerliani, J. P., Cavallin, L. E., Leung, H. J., et al. (2012). Disrupting galectin-1 interactions with $\mathrm{N}$-glycans suppresses hypoxia-driven angiogenesis and tumorigenesis in Kaposi's sarcoma. J. Exp. Med. 209, 1985-2000. doi: 10.1084/jem.20111665

Cross, M. J., and Claesson-Welsh, L. (2001). FGF and VEGF function in angiogenesis: signalling pathways, biological responses and therapeutic inhibition. Trends Pharmacol. Sci. 22, 201-207. doi: 10.1016/s0165-6147(00) 01676-x

Dai, L., Bratoeva, M., Toole, B. P., Qin, Z., and Parsons, C. (2012). KSHV activation of VEGF secretion and invasion for endothelial cells is mediated through viral upregulation of emmprin-induced signal transduction. Int. J. Cancer 131, 834-843. doi: 10.1002/ijc.26428

Dai, L., Qiao, J., Nguyen, D., Struckhoff, A. P., Doyle, L., Bonstaff, K., et al. (2016a). Role of heme oxygenase-1 in the pathogenesis and tumorigenicity of Kaposi's sarcoma-associated herpesvirus. Oncotarget 7, 10459-10471. doi: 10.18632/oncotarget.7227

Dai, L., Trillo-Tinoco, J., Chen, Y., Bonstaff, K., Del Valle, L., Parsons, C., et al. (2016b). CD147 and downstream ADAMTSs promote the tumorigenicity of Kaposi's sarcoma-associated herpesvirus infected endothelial cells. Oncotarget 7, 3806-3818. doi: 10.18632/oncotarget.6584

Dawson, C. W., Tramountanis, G., Eliopoulos, A. G., and Young, L. S. (2003). Epstein-Barr virus latent membrane protein 1 (LMP1) activates the phosphatidylinositol 3-kinase/Akt pathway to promote cell survival and induce actin filament remodeling. J. Biol. Chem. 278, 3694-3704. doi: 10.1074/jbc. M209840200

Devergne, O., Hatzivassiliou, E., Izumi, K. M., Kaye, K. M., Kleijnen, M. F., Kieff, E., et al. (1996). Association of TRAF1, TRAF2, and TRAF3 with an EpsteinBarr virus LMP1 domain important for B-lymphocyte transformation: role in NF-kappaB activation. Mol. Cell. Biol. 16, 7098-7108. doi: 10.1128/mcb.16.12. 7098

DiMaio, T. A., Gutierrez, K. D., and Lagunoff, M. (2011). Latent KSHV infection of endothelial cells induces integrin beta3 to activate angiogenic phenotypes. PLoS Pathog. 7:e1002424. doi: 10.1371/journal.ppat.1002424

DiMaio, T. A., Gutierrez, K. D., and Lagunoff, M. (2014). Kaposi's sarcomaassociated herpesvirus downregulates transforming growth factor beta2 to promote enhanced stability of capillary-like tube formation. J. Virol. 88, 1430114309. doi: 10.1128/JVI.01696-1614

Dimaio, T. A., and Lagunoff, M. (2012). KSHV Induction of Angiogenic and Lymphangiogenic Phenotypes. Front. Microbiol. 3:102. doi: 10.3389/fmicb. 2012.00102

Ding, S., Merkulova-Rainon, T., Han, Z. C., and Tobelem, G. (2003). HGF receptor up-regulation contributes to the angiogenic phenotype of human endothelial 
cells and promotes angiogenesis in vitro. Blood 101, 4816-4822. doi: 10.1182/ blood-2002-06-1731

Ding, X., Xu, J., Wang, C., Feng, Q., Wang, Q., Yang, Y., et al. (2019). Suppression of the SAP18/HDAC1 complex by targeting TRIM56 and Nanog is essential for oncogenic viral FLICE-inhibitory protein-induced acetylation of p65/RelA, NF-kappaB activation, and promotion of cell invasion and angiogenesis. Cell Death Differ. doi: 10.1038/s41418-0180268-263 [Epub ahead of print].

Dittmer, D., Lagunoff, M., Renne, R., Staskus, K., Haase, A., and Ganem, D. (1998). A cluster of latently expressed genes in Kaposi's sarcoma-associated herpesvirus. J. Virol. 72, 8309-8315.

Dittmer, D. P., and Damania, B. (2016). Kaposi sarcoma-associated herpesvirus: immunobiology, oncogenesis, and therapy. J. Clin. Invest. 126, 3165-3175. doi: $10.1172 /$ JCI84418

Dittmer, D. P., Damania, B., and Sin, S. H. (2015). Animal models of tumorigenic herpesviruses-an update. Curr. Opin. Virol. 14, 145-150. doi: 10.1016/j.coviro. 2015.09.006

Dunleavey, J. M., and Dudley, A. C. (2012). Vascular Mimicry: concepts and implications for anti-angiogenic therapy. Curr. Angiogenes 1, 133-138. doi: $10.2174 / 2211552811201020133$

Dutta, D., Chakraborty, S., Bandyopadhyay, C., Valiya Veettil, M., Ansari, M. A., Singh, V. V., et al. (2013). EphrinA2 regulates clathrin mediated KSHV endocytosis in fibroblast cells by coordinating integrin-associated signaling and c-Cbl directed polyubiquitination. PLoS Pathog. 9:e1003510. doi: 10.1371/ journal.ppat. 1003510

Dwyer, J., Le Guelte, A., Galan Moya, E. M., Sumbal, M., Carlotti, A., Douguet, L., et al. (2011). Remodeling of VE-cadherin junctions by the human herpes virus 8 G-protein coupled receptor. Oncogene 30, 190-200. doi: 10.1038/onc. 2010.411

Dyson, O. F., Bryan, B. A., Lambert, P. J., Ford, P. W., and Akula, S. M. (2007). Betal integrins mediate tubule formation induced by supernatants derived from KSHV-infected cells. Intervirology 50, 245-253. doi: 10.1159/000101995

Eliopoulos, A. G., Stack, M., Dawson, C. W., Kaye, K. M., Hodgkin, L., Sihota, S., et al. (1997). Epstein-Barr virus-encoded LMP1 and CD40 mediate IL6 production in epithelial cells via an NF-kappaB pathway involving TNF receptor-associated factors. Oncogene 14, 2899-2916. doi: 10.1038/sj.onc. 1201258

Fendri, A., Khabir, A., Hadhri-Guiga, B., Sellami-Boudawara, T., Ghorbel, A., Daoud, J., et al. (2008). Overexpression of COX-2 and LMP1 are correlated with lymph node in Tunisian NPC patients. Oral Oncol. 44, 710-715. doi: 10.1016/j.oraloncology.2007.09.006

Feyder, M., and Goff, L. A. (2016). Investigating long noncoding RNAs using animal models. J. Clin. Invest. 126, 2783-2791. doi: 10.1172/JCI84422

Field, N., Low, W., Daniels, M., Howell, S., Daviet, L., Boshoff, C., et al. (2003). KSHV vFLIP binds to IKK-gamma to activate IKK. J. Cell Sci. 116(Pt 18), 3721-3728. doi: $10.1242 /$ jcs. 00691

Flore, O., Rafii, S., Ely, S., O’Leary, J. J., Hyjek, E. M., and Cesarman, E. (1998). Transformation of primary human endothelial cells by Kaposi's sarcomaassociated herpesvirus. Nature 394, 588-592. doi: 10.1038/29093

Fonsato, V., Buttiglieri, S., Deregibus, M. C., Bussolati, B., Caselli, E., Di Luca, D., et al. (2008). PAX2 expression by HHV-8-infected endothelial cells induced a proangiogenic and proinvasive phenotype. Blood 111, 2806-2815. doi: 10.1182/ blood-2007-04-085555

Frappier, L. (2015). Ebna1. Curr. Top. Microbiol. Immunol. 391, 3-34. doi: 10.1007/ 978-3-319-22834-1_1

Fujiwara, S. (2018). Animal Models of Human Gammaherpesvirus Infections. Adv. Exp. Med. Biol. 1045, 413-436. doi: 10.1007/978-981-10-7230-7_19

Fujiwara, S., Imadome, K., and Takei, M. (2015). Modeling EBV infection and pathogenesis in new-generation humanized mice. Exp. Mol. Med. 47:e135. doi: 10.1038/emm.2014.88

Gallaher, A. M., Das, S., Xiao, Z., Andresson, T., Kieffer-Kwon, P., Happel, C., et al. (2013). Proteomic screening of human targets of viral microRNAs reveals functions associated with immune evasion and angiogenesis. PLoS Pathog. 9:e1003584. doi: 10.1371/journal.ppat.1003584

Gatto, G., Rossi, A., Rossi, D., Kroening, S., Bonatti, S., and Mallardo, M. (2008). Epstein-Barr virus latent membrane protein 1 trans-activates miR155 transcription through the NF-kappaB pathway. Nucleic Acids Res. 36, 6608-6619. doi: 10.1093/nar/gkn666
George Paul, A., Sharma-Walia, N., Kerur, N., White, C., and Chandran, B. (2010). Piracy of prostaglandin E2/EP receptor-mediated signaling by Kaposi's sarcoma-associated herpes virus (HHV-8) for latency gene expression: strategy of a successful pathogen. Cancer Res. 70, 3697-3708. doi: 10.1158/0008-5472. CAN-09-3934

Giffin, L., West, J. A., and Damania, B. (2015). Kaposi's sarcoma-associated herpesvirus interleukin- 6 modulates endothelial cell movement by upregulating cellular genes involved in migration. MBio 6, e1499-15. doi: 10.1128/mBio. 01499- 1415

Giffin, L., Yan, F., Ben Major, M., and Damania, B. (2014). Modulation of Kaposi's sarcoma-associated herpesvirus interleukin- 6 function by hypoxia-upregulated protein 1. J. Virol. 88, 9429-9441. doi: 10.1128/JVI.00511-514

Gires, O., Kohlhuber, F., Kilger, E., Baumann, M., Kieser, A., Kaiser, C., et al. (1999). Latent membrane protein 1 of Epstein-Barr virus interacts with JAK3 and activates STAT proteins. EMBO J. 18, 3064-3073. doi: 10.1093/emboj/18. 11.3064

Glenn, M., Rainbow, L., Aurade, F., Davison, A., and Schulz, T. F. (1999). Identification of a spliced gene from Kaposi's sarcoma-associated herpesvirus encoding a protein with similarities to latent membrane proteins 1 and $2 \mathrm{~A}$ of Epstein-Barr virus. J. Virol. 73, 6953-6963.

Gramolelli, S., Weidner-Glunde, M., Abere, B., Viejo-Borbolla, A., Bala, K., Ruckert, J., et al. (2015). Inhibiting the Recruitment of PLCgammal to Kaposi's Sarcoma Herpesvirus K15 Protein Reduces the Invasiveness and Angiogenesis of Infected Endothelial Cells. PLoS Pathog. 11:e1005105. doi: 10.1371/journal. ppat.1005105

Grisotto, M. G., Garin, A., Martin, A. P., Jensen, K. K., Chan, P., Sealfon, S. C., et al. (2006). The human herpesvirus 8 chemokine receptor vGPCR triggers autonomous proliferation of endothelial cells. J. Clin. Invest. 116, 1264-1273. doi: 10.1172/JCI26666

Guang-Wu, H., Sunagawa, M., Jie-En, L., Shimada, S., Gang, Z., Tokeshi, Y., et al. (2000). The relationship between microvessel density, the expression of vascular endothelial growth factor (VEGF), and the extension of nasopharyngeal carcinoma. Laryngoscope 110, 2066-2069. doi: 10.1097/00005537-200012000200012017

Guasparri, I., Keller, S. A., and Cesarman, E. (2004). KSHV vFLIP is essential for the survival of infected lymphoma cells. J. Exp. Med. 199, 993-1003. doi: 10.1084/jem.20031467

Guedez, L., McMarlin, A. J., Kingma, D. W., Bennett, T. A., Stetler-Stevenson, M., and Stetler-Stevenson, W. G. (2001). Tissue inhibitor of metalloproteinase-1 alters the tumorigenicity of Burkitt's lymphoma via divergent effects on tumor growth and angiogenesis. Am. J. Pathol. 158, 1207-1215. doi: 10.1016/S00029440(10)64070-64079

Guilluy, C., Zhang, Z., Bhende, P. M., Sharek, L., Wang, L., Burridge, K., et al. (2011). Latent KSHV infection increases the vascular permeability of human endothelial cells. Blood 118, 5344-5354. doi: 10.1182/blood-2011-03-341552

Guo, H. G., Sadowska, M., Reid, W., Tschachler, E., Hayward, G., and Reitz, M. (2003). Kaposi's sarcoma-like tumors in a human herpesvirus 8 ORF74 transgenic mouse. J. Virol. 77, 2631-2639. doi: 10.1128/jvi.77.4.2631-2639.2003

Hamza, M. S., Reyes, R. A., Izumiya, Y., Wisdom, R., Kung, H. J., and Luciw, P. A. (2004). ORF36 protein kinase of Kaposi's sarcoma herpesvirus activates the c-Jun N-terminal kinase signaling pathway. J. Biol. Chem. 279, 38325-38330. doi: $10.1074 /$ jbc.M400964200

Hanahan, D., and Weinberg, R. A. (2011). Hallmarks of cancer: the next generation. Cell 144, 646-674. doi: 10.1016/j.cell.2011.02.013

Haque, M., Wang, V., Davis, D. A., Zheng, Z. M., and Yarchoan, R. (2006). Genetic organization and hypoxic activation of the Kaposi's sarcoma-associated herpesvirus ORF34-37 gene cluster. J. Virol. 80, 7037-7051. doi: 10.1128/JVI. 00553-556

He, M., Zhang, W., Bakken, T., Schutten, M., Toth, Z., Jung, J. U., et al. (2012). Cancer angiogenesis induced by Kaposi sarcoma-associated herpesvirus is mediated by EZH2. Cancer Res. 72, 3582-3592. doi: 10.1158/0008-5472.CAN11-2876

Ho, C. H., Chen, C. L., Li, W. Y., and Chen, C. J. (2009). Decoy receptor 3, upregulated by Epstein-Barr virus latent membrane protein 1, enhances nasopharyngeal carcinoma cell migration and invasion. Carcinogenesis 30, 1443-1451. doi: 10.1093/carcin/bgp135

Holst, P. J., Rosenkilde, M. M., Manfra, D., Chen, S. C., Wiekowski, M. T., Holst, B., et al. (2001). Tumorigenesis induced by the HHV8-encoded chemokine 
receptor requires ligand modulation of high constitutive activity. J. Clin. Invest. 108, 1789-1796. doi: 10.1172/JCI13622

Hong, G. K., Gulley, M. L., Feng, W. H., Delecluse, H. J., Holley-Guthrie, E., and Kenney, S. C. (2005a). Epstein-Barr virus lytic infection contributes to lymphoproliferative disease in a SCID mouse model. J. Virol. 79, 13993-14003. doi: 10.1128/JVI.79.22.13993-14003.2005

Hong, G. K., Kumar, P., Wang, L., Damania, B., Gulley, M. L., Delecluse, H. J., et al. (2005b). Epstein-Barr virus lytic infection is required for efficient production of the angiogenesis factor vascular endothelial growth factor in lymphoblastoid cell lines. J. Virol. 79, 13984-13992. doi: 10.1128/JVI.79.22.13984-13992. 2005

Hong, Y. K., Foreman, K., Shin, J. W., Hirakawa, S., Curry, C. L., Sage, D. R., et al. (2004). Lymphatic reprogramming of blood vascular endothelium by Kaposi sarcoma-associated herpesvirus. Nat. Genet. 36, 683-685. doi: 10.1038/ ng1383

Horikawa, T., Sheen, T. S., Takeshita, H., Sato, H., Furukawa, M., and Yoshizaki, T. (2001). Induction of c-Met proto-oncogene by Epstein-Barr virus latent membrane protein- 1 and the correlation with cervical lymph node metastasis of nasopharyngeal carcinoma. Am. J. Pathol. 159, 27-33. doi: 10.1016/S00029440(10)61669-61660

Horikawa, T., Yang, J., Kondo, S., Yoshizaki, T., Joab, I., Furukawa, M., et al. (2007). Twist and epithelial-mesenchymal transition are induced by the EBV oncoprotein latent membrane protein 1 and are associated with metastatic nasopharyngeal carcinoma. Cancer Res. 67, 1970-1978. doi: 10.1158/0008-5472. CAN-06-3933

Hu, J., Jham, B. C., Ma, T., Friedman, E. R., Ferreira, L., Wright, J. M., et al. (2011). Angiopoietin-like 4: a novel molecular hallmark in oral Kaposi's sarcoma. Oral Oncol. 47, 371-375. doi: 10.1016/j.oraloncology.2011.02.018

Iwakiri, D., Eizuru, Y., Tokunaga, M., and Takada, K. (2003). Autocrine growth of Epstein-Barr virus-positive gastric carcinoma cells mediated by an Epstein-Barr virus-encoded small RNA. Cancer Res. 63, 7062-7067.

Iwakiri, D., and Takada, K. (2010). Role of EBERs in the pathogenesis of EBV infection. Adv. Cancer Res. 107, 119-136. doi: 10.1016/S0065-230X(10)070047001

Jacobs, S. R., and Damania, B. (2011). The viral interferon regulatory factors of KSHV: immunosuppressors or oncogenes? Front. Immunol. 2:19. doi: 10.3389/ fimmu.2011.00019

Jensen, K. K., Manfra, D. J., Grisotto, M. G., Martin, A. P., Vassileva, G., Kelley, K., et al. (2005). The human herpes virus 8 -encoded chemokine receptor is required for angioproliferation in a murine model of Kaposi's sarcoma. J. Immunol. 174, 3686-3694. doi: 10.4049/jimmunol.174.6.3686

Jin, T., Jiang, F., Jin, Q. F., Piao, Y. F., and Chen, X. Z. (2018). Endostar Combined with Gemcitabine and Cisplatin Chemotherapy for Patients with Metastatic Nasopharyngeal Carcinoma: an Update. Transl. Oncol. 11, 286-291. doi: 10. 1016/j.tranon.2018.01.002

Kang, G. H., Lee, S., Kim, W. H., Lee, H. W., Kim, J. C., Rhyu, M. G., et al. (2002). Epstein-barr virus-positive gastric carcinoma demonstrates frequent aberrant methylation of multiple genes and constitutes CpG island methylator phenotype-positive gastric carcinoma. Am. J. Pathol. 160, 787-794. doi: 10. 1016/S0002-9440(10)64901-64902

Karar, J., and Maity, A. (2011). PI3K/AKT/mTOR pathway in Angiogenesis. Front. Mol. Neurosci. 4:51. doi: 10.3389/fnmol.2011.00051

Kaul, R., Verma, S. C., Murakami, M., Lan, K., Choudhuri, T., and Robertson, E. S. (2006). Epstein-Barr virus protein can upregulate cyclo-oxygenase-2 expression through association with the suppressor of metastasis Nm23-H1. J. Virol. 80, 1321-1331. doi: 10.1128/JVI.80.3.1321-1331.2006

Keryer-Bibens, C., Pioche-Durieu, C., Villemant, C., Souquere, S., Nishi, N., Hirashima, M., et al. (2006). Exosomes released by EBV-infected nasopharyngeal carcinoma cells convey the viral latent membrane protein 1 and the immunomodulatory protein galectin 9. BMC Cancer 6:283. doi: 10.1186/ 1471-2407-6-283

Khorshidi, A., Dhaliwal, P., and Yang, B. B. (2016). Noncoding RNAs in Tumor Angiogenesis. Adv. Exp. Med. Biol. 927, 217-241. doi: 10.1007/978-981-101498-7_8

Kijima, Y., Hokita, S., Yoshinaka, H., Itoh, T., Koriyama, C., Eizuru, Y., et al. (2002). Amplification and overexpression of c-met gene in Epstein-Barr virus-associated gastric carcinomas. Oncology 62, 60-65. doi: 10.1159/0000 48248
Kim, J., Kim, Y. H., Kim, J., Park, D. Y., Bae, H., Lee, D. H., et al. (2017). YAP/TAZ regulates sprouting angiogenesis and vascular barrier maturation. J. Clin. Invest. 127, 3441-3461. doi: 10.1172/JCI93825

Kim, Y. W., and Byzova, T. V. (2014). Oxidative stress in angiogenesis and vascular disease. Blood 123, 625-631. doi: 10.1182/blood-2013-09-512749

King, C. A. (2013). Kaposi's sarcoma-associated herpesvirus kaposin B induces unique monophosphorylation of STAT3 at serine 727 and MK2-mediated inactivation of the STAT3 transcriptional repressor TRIM28. J. Virol. 87, 87798791. doi: 10.1128/JVI.02976-2912

Kliche, S., Nagel, W., Kremmer, E., Atzler, C., Ege, A., Knorr, T., et al. (2001). Signaling by human herpesvirus 8 kaposin A through direct membrane recruitment of cytohesin-1. Mol. Cell 7, 833-843. doi: 10.1016/s1097-2765(01) 00227- 1

Koch, A. E., Polverini, P. J., Kunkel, S. L., Harlow, L. A., Dipietro, L. A., Elner, V. M., et al. (1992). Interleukin-8 as a Macrophage-Derived Mediator of Angiogenesis. Science 258, 1798-1801. doi: 10.1126/science. 1281554

Koh, Y. W., Han, J. H., Yoon, D. H., Suh, C., and Huh, J. (2018). EpsteinBarr virus positivity is associated with angiogenesis in, and poorer survival of, patients receiving standard treatment for classical Hodgkin's lymphoma. Hematol. Oncol. 36, 182-188. doi: 10.1002/hon.2468

Kondo, S., Seo, S. Y., Yoshizaki, T., Wakisaka, N., Furukawa, M., Joab, I., et al. (2006). EBV latent membrane protein 1 up-regulates hypoxia-inducible factor 1alpha through Siah1-mediated down-regulation of prolyl hydroxylases 1 and 3 in nasopharyngeal epithelial cells. Cancer Res. 66, 9870-9877. doi: 10.1158/ 0008-5472.CAN-06-1679

Kondo, S., Wakisaka, N., Schell, M. J., Horikawa, T., Sheen, T. S., Sato, H., et al. (2005). Epstein-Barr virus latent membrane protein 1 induces the matrix metalloproteinase-1 promoter via an Ets binding site formed by a single nucleotide polymorphism: enhanced susceptibility to nasopharyngeal carcinoma. Int. J. Cancer 115, 368-376. doi: 10.1002/ijc.20849

Koon, H. B., Krown, S. E., Lee, J. Y., Honda, K., Rapisuwon, S., Wang, Z., et al. (2014). Phase II trial of imatinib in AIDS-associated Kaposi's sarcoma: AIDS Malignancy Consortium Protocol 042. J. Clin. Oncol. 32, 402-408. doi: 10.1200/ JCO.2012.48.6365

Krock, B. L., Skuli, N., and Simon, M. C. (2011). Hypoxia-induced angiogenesis: good and evil. Genes Cancer 2, 1117-1133. doi: 10.1177/1947601911423654

Kumar, B., and Chandran, B. (2016). KSHV entry and trafficking in target cellshijacking of cell signal pathways, actin and membrane dynamics. Viruses 8:E305. doi: $10.3390 / \mathrm{v} 8110305$

Kung, C. P., and Raab-Traub, N. (2008). Epstein-Barr virus latent membrane protein 1 induces expression of the epidermal growth factor receptor through effects on Bcl-3 and STAT3. J. Virol. 82, 5486-5493. doi: 10.1128/JVI.00125-128

Lagunoff, M., Majeti, R., Weiss, A., and Ganem, D. (1999). Deregulated signal transduction by the K1 gene product of Kaposi's sarcoma-associated herpesvirus. Proc. Natl. Acad. Sci. U.S.A. 96, 5704-5709. doi: 10.1073/pnas.96. 10.5704

Laing, K. G., Elia, A., Jeffrey, I., Matys, V., Tilleray, V. J., Souberbielle, B., et al. (2002). In vivo effects of the Epstein-Barr virus small RNA EBER-1 on protein synthesis and cell growth regulation. Virology 297, 253-269. doi: 10.1006/viro. 2002.1354

Lan, Y. Y., Hsiao, J. R., Chang, K. C., Chang, J. S., Chen, C. W., Lai, H. C., et al. (2012). Epstein-Barr virus latent membrane protein $2 \mathrm{~A}$ promotes invasion of nasopharyngeal carcinoma cells through ERK/Fra-1-mediated induction of matrix metalloproteinase 9. J. Virol. 86, 6656-6667. doi: 10.1128/JVI.001 74-112

Lane, B. R., Liu, J., Bock, P. J., Schols, D., Coffey, M. J., Strieter, R. M., et al. (2002). Interleukin-8 and growth-regulated oncogene alpha mediate angiogenesis in Kaposi's sarcoma. J. Virol. 76, 11570-11583. doi: 10.1128/jvi.76.22.1157011583.2002

Lee, B. S., Lee, S. H., Feng, P., Chang, H., Cho, N. H., and Jung, J. U. (2005). Characterization of the Kaposi's sarcoma-associated herpesvirus K1 signalosome. J. Virol. 79, 12173-12184. doi: 10.1128/JVI.79.19.12173-12184. 2005

Lee, H., Veazey, R., Williams, K., Li, M., Guo, J., Neipel, F., et al. (1998). Deregulation of cell growth by the K1 gene of Kaposi's sarcoma-associated herpesvirus. Nat. Med. 4, 435-440. doi: 10.1038/nm0498-435

Lee, H. R., Li, F., Choi, U. Y., Yu, H. R., Aldrovandi, G. M., Feng, P., et al. (2018). Deregulation of HDAC 5 by viral interferon regulatory factor 3 plays an essential 
role in Kaposi's sarcoma-associated herpesvirus-induced Lymphangiogenesis. MBio 9, e2217-17. doi: 10.1128/mBio.02217-2217

Lee, N. Y., Zhang, Q., Pfister, D. G., Kim, J., Garden, A. S., Mechalakos, J., et al. (2012). Addition of bevacizumab to standard chemoradiation for locoregionally advanced nasopharyngeal carcinoma (RTOG 0615): a phase 2 multi-institutional trial. Lancet Oncol. 13, 172-180. doi: 10.1016/S14702045(11)70303-70305

Li, A., Dubey, S., Varney, M. L., Dave, B. J., and Singh, R. K. (2003). IL-8 directly enhanced endothelial cell survival, proliferation, and matrix metalloproteinases production and regulated angiogenesis. J. Immunol. 170, 3369-3376. doi: 10. 4049/jimmunol.170.6.3369

Li, W., Hu, M., Wang, C., Lu, H., Chen, F., Xu, J., et al. (2017). A viral microRNA downregulates metastasis suppressor CD82 and induces cell invasion and angiogenesis by activating the c-Met signaling. Oncogene 36, 5407-5420. doi: 10.1038/onc.2017.139

Li, W., Jia, X., Shen, C., Zhang, M., Xu, J., Shang, Y., et al. (2016a). A KSHV microRNA enhances viral latency and induces angiogenesis by targeting GRK2 to activate the CXCR2/AKT pathway. Oncotarget 7, 32286-32305. doi: 10. 18632/oncotarget.8591

Li, W., Yan, Q., Ding, X., Shen, C., Hu, M., Zhu, Y., et al. (2016b). The SH3BGR/STAT3 Pathway Regulates Cell Migration and Angiogenesis Induced by a Gammaherpesvirus MicroRNA. PLoS Pathog. 12:e1005605. doi: 10.1371/ journal.ppat.1005605

Lin, S. J., Wu, S. W., Chou, Y. C., Lin, J. H., Huang, Y. C., Chen, M. R., et al. (2015). Novel expression and regulation of TIMP-1 in Epstein Barr virus-infected cells and its impact on cell survival. Virology 481, 24-33. doi: 10.1016/j.virol.2015. 02.015

Lin, W., Yip, Y. L., Jia, L., Deng, W., Zheng, H., Dai, W., et al. (2018). Establishment and characterization of new tumor xenografts and cancer cell lines from EBV-positive nasopharyngeal carcinoma. Nat. Commun. 9:4663. doi: 10.1038/ s41467-018-06889-6885

Liu, G., Yu, F. X., Kim, Y. C., Meng, Z., Naipauer, J., Looney, D. J., et al. (2015). Kaposi sarcoma-associated herpesvirus promotes tumorigenesis by modulating the Hippo pathway. Oncogene 34, 3536-3546. doi: 10.1038/onc.2014.281

Lo, A. K., Dawson, C. W., Young, L. S., Ko, C. W., Hau, P. M., and Lo, K. W. (2015). Activation of the FGFR1 signalling pathway by the Epstein-Barr virusencoded LMP1 promotes aerobic glycolysis and transformation of human nasopharyngeal epithelial cells. J. Pathol. 237, 238-248. doi: 10.1002/path.4575

Lu, F., Weidmer, A., Liu, C. G., Volinia, S., Croce, C. M., and Lieberman, P. M. (2008). Epstein-Barr virus-induced miR-155 attenuates NF-kappaB signaling and stabilizes latent virus persistence. J. Virol. 82, 10436-10443. doi: 10.1128/ JVI.00752- 758

Lu, J., Chua, H. H., Chen, S. Y., Chen, J. Y., and Tsai, C. H. (2003). Regulation of matrix metalloproteinase-1 by Epstein-Barr virus proteins. Cancer Res. 63, $256-262$.

Luo, B., Wang, Y., Wang, X. F., Gao, Y., Huang, B. H., and Zhao, P. (2006). Correlation of Epstein-Barr virus and its encoded proteins with Helicobacter pylori and expression of c-met and c-myc in gastric carcinoma. World J. Gastroenterol. 12, 1842-1848.

Lyngaa, R., Norregaard, K., Kristensen, M., Kubale, V., Rosenkilde, M. M., and Kledal, T. N. (2010). Cell transformation mediated by the Epstein-Barr virus $\mathrm{G}$ protein-coupled receptor BILF1 is dependent on constitutive signaling. Oncogene 29, 4388-4398. doi: 10.1038/onc.2010.173

Lyu, X., Wang, J., Guo, X., Wu, G., Jiao, Y., Faleti, O. D., et al. (2018). EBV-miRBART1-5P activates AMPK/mTOR/HIF1 pathway via a PTEN independent manner to promote glycolysis and angiogenesis in nasopharyngeal carcinoma. PLoS Pathog. 14:e1007484. doi: 10.1371/journal.ppat.1007484

Ma, Q., Cavallin, L. E., Leung, H. J., Chiozzini, C., Goldschmidt-Clermont, P. J., and Mesri, E. A. (2013). A role for virally induced reactive oxygen species in Kaposi's sarcoma herpesvirus tumorigenesis. Antioxid. Redox Signal. 18, 80-90. doi: 10.1089 /ars.2012.4584

Ma, Q., Cavallin, L. E., Yan, B., Zhu, S., Duran, E. M., Wang, H., et al. (2009). Antitumorigenesis of antioxidants in a transgenic Racl model of Kaposi's sarcoma. Proc. Natl. Acad. Sci. U.S.A. 106, 8683-8688. doi: 10.1073/pnas. 0812688106

Ma, S. D., Hegde, S., Young, K. H., Sullivan, R., Rajesh, D., Zhou, Y., et al. (2011). A new model of Epstein-Barr virus infection reveals an important role for early lytic viral protein expression in the development of lymphomas. J. Virol. 85, 165-177. doi: 10.1128/JVI.01512-1510

Ma, T., Jham, B. C., Hu, J., Friedman, E. R., Basile, J. R., Molinolo, A., et al. (2010). Viral G protein-coupled receptor up-regulates Angiopoietin-like 4 promoting angiogenesis and vascular permeability in Kaposi's sarcoma. Proc. Natl. Acad. Sci. U.S.A. 107, 14363-14368. doi: 10.1073/pnas.1001065107

Ma, T., Patel, H., Babapoor-Farrokhran, S., Franklin, R., Semenza, G. L., Sodhi, A., et al. (2015). KSHV induces aerobic glycolysis and angiogenesis through HIF-1dependent upregulation of pyruvate kinase 2 in Kaposi's sarcoma. Angiogenesis 18, 477-488. doi: 10.1007/s10456-015-9475-9474

Ma, W., Feng, L., Zhang, S., Zhang, H., Zhang, X., Qi, X., et al. (2018). Induction of chemokine (C-C motif) ligand 5 by Epstein-Barr virus infection enhances tumor angiogenesis in nasopharyngeal carcinoma. Cancer Sci. 109, 1710-1722. doi: $10.1111 /$ cas. 13584

Mainou, B. A., Everly, D. N. Jr., and Raab-Traub, N. (2005). Epstein-Barr virus latent membrane protein 1 CTAR1 mediates rodent and human fibroblast transformation through activation of PI3K. Oncogene 24, 6917-6924. doi: 10. 1038/sj.onc. 1208846

Mansouri, M., Rose, P. P., Moses, A. V., and Fruh, K. (2008). Remodeling of endothelial adherens junctions by Kaposi's sarcoma-associated herpesvirus. J. Virol. 82, 9615-9628. doi: 10.1128/JVI.02633-2637

Marshall, V., Parks, T., Bagni, R., Wang, C. D., Samols, M. A., Hu, J., et al. (2007). Conservation of virally encoded microRNAs in Kaposi sarcoma-associated herpesvirus in primary effusion lymphoma cell lines and in patients with Kaposi sarcoma or multicentric Castleman disease. J. Infect. Dis. 195, 645-659. doi: $10.1086 / 511434$

Masood, R., Cesarman, E., Smith, D. L., Gill, P. S., and Flore, O. (2002), Human herpesvirus-8-transformed endothelial cells have functionally activated vascular endothelial growth factor/vascular endothelial growth factor receptor. Am. J. Pathol. 160, 23-29. doi: 10.1016/S0002-9440(10)64344-64341

McCormick, C., and Ganem, D. (2005). The kaposin B protein of KSHV activates the p38/MK2 pathway and stabilizes cytokine mRNAs. Science 307, 739-741. doi: $10.1126 /$ science. 1105779

McHugh, D., Caduff, N., Barros, M. H. M., Ramer, P. C., Raykova, A., Murer, A., et al. (2017). Persistent KSHV infection increases EBV-associated tumor formation in vivo via enhanced EBV lytic gene expression. Cell Host Microbe 22, 61-73.e7. doi: 10.1016/j.chom.2017.06.009

Meckes, D. G. Jr., Shair, K. H., Marquitz, A. R., Kung, C. P., Edwards, R. H., and Raab-Traub, N. (2010). Human tumor virus utilizes exosomes for intercellular communication. Proc. Natl. Acad. Sci. U.S.A. 107, 20370-20375. doi: 10.1073/ pnas. 1014194107

Mesri, E. A., Feitelson, M. A., and Munger, K. (2014). Human viral oncogenesis: a cancer hallmarks analysis. Cell Host Microbe 15, 266-282. doi: 10.1016/j.chom. 2014.02.011

Miller, W. E., Earp, H. S., and Raab-Traub, N. (1995). The Epstein-Barr virus latent membrane protein 1 induces expression of the epidermal growth factor receptor. J. Virol. 69, 4390-4398.

Mironchik, Y., Winnard, P. T. Jr., Vesuna, F., Kato, Y., Wildes, F., Pathak, A. P., et al. (2005). Twist overexpression induces in vivo angiogenesis and correlates with chromosomal instability in breast cancer. Cancer Res. 65, 10801-10809. doi: 10.1158/0008-5472.CAN-05-0712

Molden, J., Chang, Y., You, Y., Moore, P. S., and Goldsmith, M. A. (1997). A Kaposi's sarcoma-associated herpesvirus-encoded cytokine homolog (vIL-6) activates signaling through the shared gp130 receptor subunit. J. Biol. Chem. 272, 19625-19631. doi: 10.1074/jbc.272.31.19625

Montaner, S., Sodhi, A., Molinolo, A., Bugge, T. H., Sawai, E. T., He, Y., et al. (2003). Endothelial infection with KSHV genes in vivo reveals that VGPCR initiates Kaposi's sarcomagenesis and can promote the tumorigenic potential of viral latent genes. Cancer Cell 3, 23-36. doi: 10.1016/s1535-6108(02)00237-4

Montaner, S., Sodhi, A., Pece, S., Mesri, E. A., and Gutkind, J. S. (2001). The Kaposi's sarcoma-associated herpesvirus $\mathrm{G}$ protein-coupled receptor promotes endothelial cell survival through the activation of Akt/protein kinase B. Cancer Res. 61, 2641-2648.

Montaner, S., Sodhi, A., Servitja, J. M., Ramsdell, A. K., Barac, A., Sawai, E. T., et al. (2004). The small GTPase Rac1 links the Kaposi sarcoma-associated herpesvirus vGPCR to cytokine secretion and paracrine neoplasia. Blood 104, 2903-2911. doi: 10.1182/blood-2003-12-4436 
Moore, P. S., Boshoff, C., Weiss, R. A., and Chang, Y. (1996). Molecular mimicry of human cytokine and cytokine response pathway genes by KSHV. Science 274, 1739-1744. doi: 10.1126/science.274.5293.1739

Mori, Y., Nishimoto, N., Ohno, M., Inagi, R., Dhepakson, P., Amou, K., et al. (2000). Human herpesvirus 8-encoded interleukin-6 homologue (viral IL-6) induces endogenous human IL-6 secretion. J. Med. Virol. 61, 332-335. doi: 10.1002/1096-9071(200007)61:3<332::aid-jmv8>3.0.co;2-3

Morris, V. A., Punjabi, A. S., Wells, R. C., Wittkopp, C. J., Vart, R., and Lagunoff, M. (2012). The KSHV viral IL-6 homolog is sufficient to induce blood to lymphatic endothelial cell differentiation. Virology 428, 112-120. doi: 10.1016/j.virol.2012. 03.013

Morrison, J. A., Klingelhutz, A. J., and Raab-Traub, N. (2003). Epstein-Barr virus latent membrane protein $2 \mathrm{~A}$ activates beta-catenin signaling in epithelial cells. J. Virol. 77, 12276-12284. doi: 10.1128/jvi.77.22.12276-12284.2003

Mosialos, G., Birkenbach, M., Yalamanchili, R., VanArsdale, T., Ware, C., and Kieff, E. (1995). The Epstein-Barr virus transforming protein LMP1 engages signaling proteins for the tumor necrosis factor receptor family. Cell 80, 389-399. doi: 10.1016/0092-8674(95)90489-1

Munz, C. (2017). Humanized mouse models for Epstein Barr virus infection. Curr. Opin. Virol. 25, 113-118. doi: 10.1016/j.coviro.2017.07.026

Murakami, Y., Yamagoe, S., Noguchi, K., Takebe, Y., Takahashi, N., Uehara, Y., et al. (2006). Ets-1-dependent expression of vascular endothelial growth factor receptors is activated by latency-associated nuclear antigen of Kaposi's sarcomaassociated herpesvirus through interaction with Daxx. J. Biol. Chem. 281, 28113-28121. doi: 10.1074/jbc.M602026200

Murono, S., Inoue, H., Tanabe, T., Joab, I., Yoshizaki, T., Furukawa, M., et al. (2001). Induction of cyclooxygenase- 2 by Epstein-Barr virus latent membrane protein 1 is involved in vascular endothelial growth factor production in nasopharyngeal carcinoma cells. Proc. Natl. Acad. Sci. U.S.A. 98, 6905-6910. doi: 10.1073/pnas.121016998

Mutlu, A. D., Cavallin, L. E., Vincent, L., Chiozzini, C., Eroles, P., Duran, E. M., et al. (2007). In vivo-restricted and reversible malignancy induced by human herpesvirus-8 KSHV: a cell and animal model of virally induced Kaposi's sarcoma. Cancer Cell 11, 245-258. doi: 10.1016/j.ccr.2007.01.015

Nakayama, K., Frew, I. J., Hagensen, M., Skals, M., Habelhah, H., Bhoumik, A., et al. (2004). Siah2 regulates stability of prolyl-hydroxylases, controls HIF1alpha abundance, and modulates physiological responses to hypoxia. Cell 117, 941952. doi: 10.1016/j.cell.2004.06.001

Nanbo, A., Inoue, K., Adachi-Takasawa, K., and Takada, K. (2002). Epstein-Barr virus RNA confers resistance to interferon-alpha-induced apoptosis in Burkitt's lymphoma. EMBO J. 21, 954-965. doi: 10.1093/emboj/21.5.954

Neipel, F., Albrecht, J. C., Ensser, A., Huang, Y. Q., Li, J. J., Friedman-Kien, A. E., et al. (1997). Human herpesvirus 8 encodes a homolog of interleukin-6. J. Virol. 71, 839-842.

Nicholas, J., Ruvolo, V. R., Burns, W. H., Sandford, G., Wan, X., Ciufo, D., et al. (1997). Kaposi's sarcoma-associated human herpesvirus- 8 encodes homologues of macrophage inflammatory protein-1 and interleukin-6. Nat. Med. 3, 287292. doi: 10.1038/nm0397-287

Nowak-Sliwinska, P., Segura, T., and Iruela-Arispe, M. L. (2014). The chicken chorioallantoic membrane model in biology, medicine and bioengineering. Angiogenesis 17, 779-804. doi: 10.1007/s10456-014-9440-9447

O’Hara, A. J., Chugh, P., Wang, L., Netto, E. M., Luz, E., Harrington, W. J., et al. (2009a). Pre-micro RNA signatures delineate stages of endothelial cell transformation in Kaposi sarcoma. PLoS Pathog. 5:e1000389. doi: 10.1371/ journal.ppat.1000389

O’Hara, A. J., Wang, L., Dezube, B. J., Harrington, W. J. Jr., Damania, B., Dittmer, D. P., et al. (2009b). Tumor suppressor microRNAs are underrepresented in primary effusion lymphoma and Kaposi sarcoma. Blood 113, 5938-5941. doi: 10.1182/blood-2008-09-179168

Okabe, A., Funata, S., Matsusaka, K., Namba, H., Fukuyo, M., Rahmutulla, B., et al. (2017). Regulation of tumour related genes by dynamic epigenetic alteration at enhancer regions in gastric epithelial cells infected by Epstein-Barr virus. Sci. Rep. 7:7924. doi: 10.1038/s41598-017-08370-8377

O’Neil, J. D., Owen, T. J., Wood, V. H., Date, K. L., Valentine, R., Chukwuma, M. B., et al. (2008). Epstein-Barr virus-encoded EBNA1 modulates the AP-1 transcription factor pathway in nasopharyngeal carcinoma cells and enhances angiogenesis in vitro. J. Gen. Virol. 89(Pt 11), 2833-2842. doi: 10.1099/vir.0. 2008/003392-3390
Park, J., Lee, D., Seo, T., Chung, J., and Choe, J. (2000). Kaposi's sarcoma-associated herpesvirus (human herpesvirus-8) open reading frame 36 protein is a serine protein kinase. J. Gen. Virol. 81(Pt 4), 1067-1071. doi: 10.1099/0022-1317-814- 1067

Paulsen, S. J., Rosenkilde, M. M., Eugen-Olsen, J., and Kledal, T. N. (2005). EpsteinBarr virus-encoded BILF1 is a constitutively active $G$ protein-coupled receptor. J. Virol. 79, 536-546. doi: 10.1128/JVI.79.1.536-546.2005

Paydas, S., Ergin, M., Erdogan, S., and Seydaoglu, G. (2008). Prognostic significance of EBV-LMP1 and VEGF-A expressions in non-Hodgkin's lymphomas. Leuk. Res. 32, 1424-1430. doi: 10.1016/j.leukres.2008.01.008

Pfeffer, S., Sewer, A., Lagos-Quintana, M., Sheridan, R., Sander, C., Grasser, F. A., et al. (2005). Identification of microRNAs of the herpesvirus family. Nat. Methods 2, 269-276. doi: 10.1038/nmeth746

Plummer, M., de Martel, C., Vignat, J., Ferlay, J., Bray, F., and Franceschi, S. (2016). Global burden of cancers attributable to infections in 2012: a synthetic analysis. Lancet Glob. Health 4, e609-e616. doi: 10.1016/S2214-109X(16)30143-30147

Polizzotto, M. N., Uldrick, T. S., Wyvill, K. M., Aleman, K., Peer, C. J., Bevans, M., et al. (2016). Pomalidomide for symptomatic Kaposi's Sarcoma in people with and without HIV infection: a Phase I/II Study. J. Clin. Oncol. 34, 4125-4131. doi: 10.1200/JCO.2016.69.3812

Portis, T., Dyck, P., and Longnecker, R. (2003). Epstein-Barr Virus (EBV) LMP2A induces alterations in gene transcription similar to those observed in ReedSternberg cells of Hodgkin lymphoma. Blood 102, 4166-4178. doi: 10.1182/ blood-2003-04-1018

Portis, T., and Longnecker, R. (2004). Epstein-Barr virus (EBV) LMP2A mediates B-lymphocyte survival through constitutive activation of the Ras/PI3K/Akt pathway. Oncogene 23, 8619-8628. doi: 10.1038/sj.onc.1207905

Principe, D. R., Doll, J. A., Bauer, J., Jung, B., Munshi, H. G., Bartholin, L., et al. (2014). TGF-beta: duality of function between tumor prevention and carcinogenesis. J. Natl. Cancer Inst. 106, djt369. doi: 10.1093/jnci/djt369

Punj, V., Matta, H., Schamus, S., and Chaudhary, P. M. (2009). Integrated microarray and multiplex cytokine analyses of Kaposi's Sarcoma Associated Herpesvirus viral FLICE Inhibitory Protein K13 affected genes and cytokines in human blood vascular endothelial cells. BMC Med. Genomics 2:50. doi: 10.1186/1755-8794-2-50

Purushothaman, P., Uppal, T., Sarkar, R., and Verma, S. C. (2016). KSHV-mediated angiogenesis in tumor progression. Viruses 8:198. doi: 10.3390/v8070198

Qian, C. N., Zhang, C. Q., Guo, X., Hong, M. H., Cao, S. M., Mai, W. Y., et al. (2000). Elevation of serum vascular endothelial growth factor in male patients with metastatic nasopharyngeal carcinoma. Cancer 88, 255-261. doi: 10.1002/ (sici) 1097-0142(20000115)88:2<255::aid-cncr2>3.3.co;2-e

Qian, L. W., Greene, W., Ye, F., and Gao, S. J. (2008). Kaposi's sarcoma-associated herpesvirus disrupts adherens junctions and increases endothelial permeability by inducing degradation of VE-cadherin. J. Virol. 82, 11902-11912. doi: 10. 1128/JVI.01042-1048

Qian, L. W., Xie, J., Ye, F., and Gao, S. J. (2007). Kaposi's sarcoma-associated herpesvirus infection promotes invasion of primary human umbilical vein endothelial cells by inducing matrix metalloproteinases. J. Virol. 81, 7001-7010. doi: 10.1128/JVI.00016-17

Qin, Z., Dai, L., Slomiany, M. G., Toole, B. P., and Parsons, C. (2010). Direct activation of emmprin and associated pathogenesis by an oncogenic herpesvirus. Cancer Res. 70, 3884-3889. doi: 10.1158/0008-5472.CAN-09-4663

Ramalingam, D., Happel, C., and Ziegelbauer, J. M. (2015). Kaposi's sarcomaassociated herpesvirus microRNAs repress breakpoint cluster region protein expression, enhance Racl activity, and increase in vitro angiogenesis. J. Virol. 89, 4249-4261. doi: 10.1128/JVI.03687-3614

Ribeiro, A., Abreu, R. M. V., Dias, M. M., Barreiro, M. F., and Ferreira, I. (2018). Antiangiogenic compounds: well-established drugs versus emerging natural molecules. Cancer Lett. 415, 86-105. doi: 10.1016/j.canlet.2017.12.006

Rivas, C., Thlick, A. E., Parravicini, C., Moore, P. S., and Chang, Y. (2001). Kaposi's sarcoma-associated herpesvirus LANA2 is a B-cell-specific latent viral protein that inhibits p53. J. Virol. 75, 429-438. doi: 10.1128/JVI.75.1.429-438.2001

Roy, D., Sin, S. H., Lucas, A., Venkataramanan, R., Wang, L., Eason, A., et al. (2013). mTOR inhibitors block Kaposi sarcoma growth by inhibiting essential autocrine growth factors and tumor angiogenesis. Cancer Res. 73, 2235-2246. doi: 10.1158/0008-5472.CAN-12-1851

Rundhaug, J. E. (2005). Matrix metalloproteinases and angiogenesis. J. Cell. Mol. Med. 9, 267-285. 
Sadagopan, S., Sharma-Walia, N., Veettil, M. V., Bottero, V., Levine, R., Vart, R. J., et al. (2009). Kaposi's sarcoma-associated herpesvirus upregulates angiogenin during infection of human dermal microvascular endothelial cells, which induces $45 \mathrm{~S}$ rRNA synthesis, antiapoptosis, cell proliferation, migration, and angiogenesis. J. Virol. 83, 3342-3364. doi: 10.1128/JVI.02052-2058

Sakakibara, S., and Tosato, G. (2009). Regulation of angiogenesis in malignancies associated with Epstein-Barr virus and Kaposi's sarcoma-associated herpes virus. Future Microbiol. 4, 903-917. doi: 10.2217/fmb.09.49

Samaniego, F., Markham, P. D., Gendelman, R., Watanabe, Y., Kao, V., Kowalski, K., et al. (1998). Vascular endothelial growth factor and basic fibroblast growth factor present in Kaposi's sarcoma (KS) are induced by inflammatory cytokines and synergize to promote vascular permeability and KS lesion development. Am. J. Pathol. 152, 1433-1443.

Samols, M. A., Hu, J., Skalsky, R. L., and Renne, R. (2005). Cloning and identification of a microRNA cluster within the latency-associated region of Kaposi's sarcoma-associated herpesvirus. J. Virol. 79, 9301-9305. doi: 10.1128/ JVI.79.14.9301-9305.2005

Samols, M. A., Skalsky, R. L., Maldonado, A. M., Riva, A., Lopez, M. C., Baker, H. V., et al. (2007). Identification of cellular genes targeted by KSHV-encoded microRNAs. PLoS Pathog. 3:e65. doi: 10.1371/journal.ppat.0030065

Schorey, J. S., and Bhatnagar, S. (2008). Exosome function: from tumor immunology to pathogen biology. Traffic 9, 871-881. doi: 10.1111/j.1600-0854. 2008.00734.x

Schwarz, M., and Murphy, P. M. (2001). Kaposi's sarcoma-associated herpesvirus G protein-coupled receptor constitutively activates NF-kappa B and induces proinflammatory cytokine and chemokine production via a C-terminal signaling determinant. J. Immunol. 167, 505-513. doi: 10.4049/jimmunol.167. 1.505

Seghezzi, G., Patel, S., Ren, C. J., Gualandris, A., Pintucci, G., Robbins, E. S., et al. (1998). Fibroblast growth factor-2 (FGF-2) induces vascular endothelial growth factor (VEGF) expression in the endothelial cells of forming capillaries: an autocrine mechanism contributing to angiogenesis. J. Cell Biol. 141, 1659-1673. doi: 10.1083/jcb.141.7.1659

Shan, B., Morris, C. A., Zhuo, Y., Shelby, B. D., Levy, D. R., and Lasky, J. A. (2007). Activation of proMMP-2 and Src by HHV8 vGPCR in human pulmonary arterial endothelial cells. J. Mol. Cell. Cardiol. 42, 517-525. doi: 10.1016/j.yjmcc. 2006.08.004

Sharma-Walia, N., Patel, K., Chandran, K., Marginean, A., Bottero, V., Kerur, N., et al. (2012). COX-2/PGE2: molecular ambassadors of Kaposi's sarcomaassociated herpes virus oncoprotein-v-FLIP. Oncogenesis 1, e5. doi: 10.1038/ oncsis. 2012.5

Sharma-Walia, N., Paul, A. G., Bottero, V., Sadagopan, S., Veettil, M. V., Kerur, N., et al. (2010). Kaposi's sarcoma associated herpes virus (KSHV) induced COX-2: a key factor in latency, inflammation, angiogenesis, cell survival and invasion. PLoS Pathog. 6:e1000777. doi: 10.1371/journal.ppat.1000777

Sharma-Walia, N., Raghu, H., Sadagopan, S., Sivakumar, R., Veettil, M. V., Naranatt, P. P., et al. (2006). Cyclooxygenase 2 induced by Kaposi's sarcomaassociated herpesvirus early during in vitro infection of target cells plays a role in the maintenance of latent viral gene expression. J. Virol. 80, 6534-6552. doi: 10.1128/JVI.00231-236

Shi, J., and Wei, P. K. (2016). Interleukin-8: a potent promoter of angiogenesis in gastric cancer. Oncol. Lett. 11, 1043-1050. doi: 10.3892/ol.2015.4035

Shin, Y. C., Joo, C. H., Gack, M. U., Lee, H. R., and Jung, J. U. (2008). Kaposi's sarcoma-associated herpesvirus viral IFN regulatory factor 3 stabilizes hypoxia-inducible factor- 1 alpha to induce vascular endothelial growth factor expression. Cancer Res. 68, 1751-1759. doi: 10.1158/0008-5472.CAN-072766

Shiomi, T., and Okada, Y. (2003). MT1-MMP and MMP-7 in invasion and metastasis of human cancers. Cancer Metastasis Rev. 22, 145-152.

Sin, S. H., Roy, D., Wang, L., Staudt, M. R., Fakhari, F. D., Patel, D. D., et al. (2007). Rapamycin is efficacious against primary effusion lymphoma (PEL) cell lines in vivo by inhibiting autocrine signaling. Blood 109, 2165-2173. doi: 10.1182/blood-2006-06-028092

Sivakumar, R., Sharma-Walia, N., Raghu, H., Veettil, M. V., Sadagopan, S., Bottero, V., et al. (2008). Kaposi's sarcoma-associated herpesvirus induces sustained levels of vascular endothelial growth factors A and C early during in vitro infection of human microvascular dermal endothelial cells: biological implications. J. Virol. 82, 1759-1776. doi: 10.1128/JVI.00873-877
Smith, P. A., Merritt, D., Barr, L., and Thorley-Lawson, D. A. (2011). An orthotopic model of metastatic nasopharyngeal carcinoma and its application in elucidating a therapeutic target that inhibits metastasis. Genes Cancer 2, 1023-1033. doi: $10.1177 / 1947601912440878$

Sobrino, A., Phan, D. T., Datta, R., Wang, X., Hachey, S. J., Romero-Lopez, M., et al. (2016). 3D microtumors in vitro supported by perfused vascular networks. Sci. Rep. 6:31589. doi: 10.1038/srep31589

Sodhi, A., Chaisuparat, R., Hu, J., Ramsdell, A. K., Manning, B. D., Sausville, E. A., et al. (2006). The TSC2/mTOR pathway drives endothelial cell transformation induced by the Kaposi's sarcoma-associated herpesvirus G protein-coupled receptor. Cancer Cell 10, 133-143. doi: 10.1016/j.ccr.2006.05.026

Sodhi, A., Montaner, S., Patel, V., Gomez-Roman, J. J., Li, Y., Sausville, E. A., et al. (2004). Akt plays a central role in sarcomagenesis induced by Kaposi's sarcoma herpesvirus-encoded G protein-coupled receptor. Proc. Natl. Acad. Sci. U.S.A 101, 4821-4826. doi: 10.1073/pnas.0400835101

Sodhi, A., Montaner, S., Patel, V., Zohar, M., Bais, C., Mesri, E. A., et al. (2000). The Kaposi's sarcoma-associated herpes virus G protein-coupled receptor up-regulates vascular endothelial growth factor expression and secretion through mitogen-activated protein kinase and $\mathrm{p} 38$ pathways acting on hypoxiainducible factor 1alpha. Cancer Res. 60, 4873-4880.

Sousa-Squiavinato, A. C., Silvestre, R. N., and Elgui De Oliveira, D. (2015). Biology and oncogenicity of the Kaposi sarcoma herpesvirus K1 protein. Rev. Med. Virol. 25, 273-285. doi: 10.1002/rmv.1843

Stallone, G., Schena, A., Infante, B., Di Paolo, S., Loverre, A., Maggio, G., et al. (2005). Sirolimus for Kaposi's sarcoma in renal-transplant recipients. N. Engl. J. Med. 352, 1317-1323. doi: 10.1056/NEJMoa042831

Stine, J. T., Wood, C., Hill, M., Epp, A., Raport, C. J., Schweickart, V. L., et al. (2000). KSHV-encoded CC chemokine vMIP-III is a CCR4 agonist, stimulates angiogenesis, and selectively chemoattracts TH2 cells. Blood 95, 1151-1157.

Su, M., Xiao, Y., Ma, J., Tang, Y., Tian, B., Zhang, Y., et al. (2019). Circular RNAs in Cancer: emerging functions in hallmarks, stemness, resistance and roles as potential biomarkers. Mol. Cancer 18:90. doi: 10.1186/s12943-019-10021006

Suthaus, J., Stuhlmann-Laeisz, C., Tompkins, V. S., Rosean, T. R., Klapper, W., Tosato, G., et al. (2012). HHV-8-encoded viral IL-6 collaborates with mouse IL-6 in the development of multicentric Castleman disease in mice. Blood 119, 5173-5181. doi: 10.1182/blood-2011-09-377705

Swaminathan, S., Tomkinson, B., and Kieff, E. (1991). Recombinant EpsteinBarr virus with small RNA (EBER) genes deleted transforms lymphocytes and replicates in vitro. Proc. Natl. Acad. Sci. U.S.A. 88, 1546-1550. doi: 10.1073/ pnas.88.4.1546

Szpakowska, M., and Chevigne, A. (2016). vCCL2/vMIP-II, the viral master KEYmokine. J. Leukoc. Biol. 99, 893-900. doi: 10.1189/jlb.2MR0815-383R

Tagawa, T., Gao, S., Koparde, V. N., Gonzalez, M., Spouge, J. L., Serquina, A. P., et al. (2018). Discovery of Kaposi's sarcoma herpesvirus-encoded circular RNAs and a human antiviral circular RNA. Proc. Natl. Acad. Sci. U.S.A. 115, 12805-12810. doi: 10.1073/pnas.1816183115

Takeshita, H., Yoshizaki, T., Miller, W. E., Sato, H., Furukawa, M., Pagano, J. S., et al. (1999). Matrix metalloproteinase 9 expression is induced by Epstein-Barr virus latent membrane protein $1 \mathrm{C}$-terminal activation regions 1 and 2. J. Virol. 73, 5548-5555.

Taraboletti, G., Benelli, R., Borsotti, P., Rusnati, M., Presta, M., Giavazzi, R., et al. (1999). Thrombospondin-1 inhibits Kaposi's sarcoma (KS) cell and HIV-1 Tatinduced angiogenesis and is poorly expressed in KS lesions. J. Pathol. 188, $76-81$.

Thakker, S., Strahan, R. C., Scurry, A. N., Uppal, T., and Verma, S. C. (2018). KSHV LANA upregulates the expression of epidermal growth factor like domain 7 to promote angiogenesis. Oncotarget 9, 1210-1228. doi: 10.18632/oncotarget. 23456

Thornburg, N. J., and Raab-Traub, N. (2007). Induction of epidermal growth factor receptor expression by Epstein-Barr virus latent membrane protein 1 C-terminal-activating region 1 is mediated by NF-kappaB p 50 homodimer/Bcl3 complexes. J. Virol. 81, 12954-12961. doi: 10.1128/JVI.016011607

Thurston, G., and Daly, C. (2012). The complex role of angiopoietin-2 in the angiopoietin-tie signaling pathway. Cold Spring Harb. Perspect Med. 2:a006550. doi: $10.1101 /$ cshperspect.a006650 
Tomlinson, C. C., and Damania, B. (2004). The K1 protein of Kaposi's sarcomaassociated herpesvirus activates the Akt signaling pathway. J. Virol. 78, 19181927. doi: 10.1128/jvi.78.4.1918-1927.2004

Toptan, T., Abere, B., Nalesnik, M. A., Swerdlow, S. H., Ranganathan, S., Lee, N., et al. (2018). Circular DNA tumor viruses make circular RNAs. Proc. Natl. Acad. Sci. U.S.A. 115, E8737-E8745. doi: 10.1073/pnas.1811728115

Tsuji, A., Wakisaka, N., Kondo, S., Murono, S., Furukawa, M., and Yoshizaki, T. (2008). Induction of receptor for advanced glycation end products by EBV latent membrane protein 1 and its correlation with angiogenesis and cervical lymph node metastasis in nasopharyngeal carcinoma. Clin. Cancer Res. 14, 5368-5375. doi: 10.1158/1078-0432.CCR-08-0198

Uldrick, T. S., Wyvill, K. M., Kumar, P., O’Mahony, D., Bernstein, W., Aleman, K., et al. (2012). Phase II study of bevacizumab in patients with HIV-associated Kaposi's sarcoma receiving antiretroviral therapy. J. Clin. Oncol. 30, 1476-1483. doi: 10.1200/JCO.2011.39.6853

Ungerleider, N., Concha, M., Lin, Z., Roberts, C., Wang, X., Cao, S., et al. (2018). The Epstein Barr virus circRNAome. PLoS Pathog. 14:e1007206. doi: 10.1371/ journal.ppat.1007206

Ungerleider, N. A., Jain, V., Wang, Y., Maness, N. J., Blair, R. V., Alvarez, X., et al. (2019). Comparative analysis of Gammaherpesvirus circular RNA repertoires: conserved and unique viral circular RNAs. J. Virol. 93, e1952-18. doi: 10.1128/ JVI.01952-1918

van Rhee, F., Wong, R. S., Munshi, N., Rossi, J. F., Ke, X. Y., Fossa, A., et al. (2014). Siltuximab for multicentric Castleman's disease: a randomised, doubleblind, placebo-controlled trial. Lancet Oncol. 15, 966-974. doi: 10.1016/S14702045(14)70319-70315

Vart, R. J., Nikitenko, L. L., Lagos, D., Trotter, M. W., Cannon, M., Bourboulia, D., et al. (2007). Kaposi's sarcoma-associated herpesvirus-encoded interleukin6 and G-protein-coupled receptor regulate angiopoietin-2 expression in lymphatic endothelial cells. Cancer Res. 67, 4042-4051. doi: 10.1158/0008-5472. CAN-06-3321

Wakisaka, N., Kondo, S., Yoshizaki, T., Murono, S., Furukawa, M., and Pagano, J. S. (2004). Epstein-Barr virus latent membrane protein 1 induces synthesis of hypoxia-inducible factor 1 alpha. Mol. Cell. Biol. 24, 5223-5234. doi: 10.1128/ MCB.24.12.5223-5234.2004

Wakisaka, N., Murono, S., Yoshizaki, T., Furukawa, M., and Pagano, J. S. (2002). Epstein-barr virus latent membrane protein 1 induces and causes release of fibroblast growth factor-2. Cancer Res. 62, 6337-6344.

Wakisaka, N., Wen, Q. H., Yoshizaki, T., Nishimura, T., Furukawa, M., Kawahara, E., et al. (1999). Association of vascular endothelial growth factor expression with angiogenesis and lymph node metastasis in nasopharyngeal carcinoma. Laryngoscope 109, 810-814. doi: 10.1097/00005537-199905000-00024

Wang, D., Liebowitz, D., and Kieff, E. (1985). An EBV membrane protein expressed in immortalized lymphocytes transforms established rodent cells. Cell 43(3 Pt 2), 831-840. doi: 10.1016/0092-8674(85)90256-9

Wang, L., and Damania, B. (2008). Kaposi's sarcoma-associated herpesvirus confers a survival advantage to endothelial cells. Cancer Res. 68, 4640-4648. doi: 10. 1158/0008-5472.CAN-07-5988

Wang, L., Dittmer, D. P., Tomlinson, C. C., Fakhari, F. D., and Damania, B. (2006). Immortalization of primary endothelial cells by the $\mathrm{K} 1$ protein of Kaposi's sarcoma-associated herpesvirus. Cancer Res. 66, 3658-3666. doi: 10.1158/00085472.CAN-05-3680

Wang, L., Wakisaka, N., Tomlinson, C. C., DeWire, S. M., Krall, S., Pagano, J. S., et al. (2004). The Kaposi's sarcoma-associated herpesvirus (KSHV/HHV-8) K1 protein induces expression of angiogenic and invasion factors. Cancer Res. 64, 2774-2781. doi: 10.1158/0008-5472.can-03-3653

Wang, M., Yu, F., Wu, W., Wang, Y., Ding, H., and Qian, L. (2018). Epstein-Barr virus-encoded microRNAs as regulators in host immune responses. Int. J. Biol. Sci. 14, 565-576. doi: 10.7150/ijbs.24562

Wang, X., He, Z., Xia, T., Li, X., Liang, D., Lin, X., et al. (2014). Latencyassociated nuclear antigen of Kaposi sarcoma-associated herpesvirus promotes angiogenesis through targeting notch signaling effector Heyl. Cancer Res. 74, 2026-2037. doi: 10.1158/0008-5472.CAN-13-1467

Wang, Z., Luo, F., Li, L., Yang, L., Hu, D., Ma, X., et al. (2010). STAT3 activation induced by Epstein-Barr virus latent membrane protein 1 causes vascular endothelial growth factor expression and cellular invasiveness via JAK3 And ERK signaling. Eur. J. Cancer 46, 2996-3006. doi: 10.1016/j.ejca.2010. 07.008
Waugh, D. J. J., and Wilson, C. (2008). The Interleukin-8 Pathway in Cancer. Clin. Cancer Res. 14, 6735-6741. doi: 10.1158/1078-0432.Ccr-07-4843

Weidner-Glunde, M., Mariggio, G., and Schulz, T. F. (2017). Kaposi's sarcomaassociated herpesvirus latency-associated nuclear antigen: replicating and shielding viral DNA during viral persistence. J. Virol. 91, e1083-16. doi: 10. 1128/JVI.01083-1016

Weis, S. M., and Cheresh, D. A. (2011). Tumor angiogenesis: molecular pathways and therapeutic targets. Nat. Med. 17:1359. doi: 10.1038/nm.2537

Wilson, J. B., Manet, E., Gruffat, H., Busson, P., Blondel, M., and Fahraeus, R. (2018). EBNA1: oncogenic activity, immune evasion and biochemical functions provide targets for novel therapeutic strategies against Epstein-Barr Virusassociated cancers. Cancers 10, E109. doi: 10.3390/cancers10040109

Wong, J. P., and Damania, B. (2017). Modulation of oncogenic signaling networks by Kaposi's sarcoma-associated herpesvirus. Biol. Chem. 398, 911-918. doi: 10.1515/hsz-2017-2101

Wood, V. H., O’Neil, J. D., Wei, W., Stewart, S. E., Dawson, C. W., and Young, L. S. (2007). Epstein-Barr virus-encoded EBNA1 regulates cellular gene transcription and modulates the STAT1 and TGFbeta signaling pathways. Oncogene 26, 4135-4147. doi: 10.1038/sj.onc.1210496

Woodford, N. L., Call, D. R., Remick, D. G., and Rochford, R. (2004). Model of angiogenesis in mice with severe combined immunodeficiency (SCID) and xenoengrafted with Epstein-Barr virus-transformed B cells. Comp. Med. 54, 209-215.

Wu, J., Xu, Y., Mo, D., Huang, P., Sun, R., Huang, L., et al. (2014). Kaposi's sarcoma-associated herpesvirus (KSHV) vIL-6 promotes cell proliferation and migration by upregulating DNMT1 via STAT3 activation. PLoS One 9:e93478. doi: 10.1371/journal.pone.0093478

Wu, Y. H., Hu, T. F., Chen, Y. C., Tsai, Y. N., Tsai, Y. H., Cheng, C. C., et al. (2011). The manipulation of miRNA-gene regulatory networks by KSHV induces endothelial cell motility. Blood 118, 2896-2905. doi: 10.1182/blood-2011-01330589

Xiang, T., Lin, Y. X., Ma, W., Zhang, H. J., Chen, K. M., He, G. P., et al. (2018). Vasculogenic mimicry formation in EBV-associated epithelial malignancies. Nat. Commun. 9:5009. doi: 10.1038/s41467-018-07308-7305

Xie, L. Q., Bian, L. J., Li, Z., Li, Y., and Liang, Y. J. (2010). Co-elevated expression of hepatocyte growth factor and Interleukin-8 contributes to poor prognosis of patients with primary nasopharyngeal carcinoma. Oncol. Rep. 23, 141-150.

Xu, S., Bai, J., Zhuan, Z., Li, B., Zhang, Z., Wu, X., et al. (2018). EBVLMP1 is involved in vasculogenic mimicry formation via VEGFA/VEGFR1 signaling in nasopharyngeal carcinoma. Oncol. Rep. 40, 377-384. doi: 10.3892/or.2018.6414

Xue, M., Yao, S., Hu, M., Li, W., Hao, T., Zhou, F., et al. (2014). HIV-1 Nef and KSHV oncogene K1 synergistically promote angiogenesis by inducing cellular miR-718 to regulate the PTEN/AKT/mTOR signaling pathway. Nucleic Acids Res. 42, 9862-9879. doi: 10.1093/nar/gku583

Yamagishi, S., Yonekura, H., Yamamoto, Y., Katsuno, K., Sato, F., Mita, I., et al. (1997). Advanced glycation end products-driven angiogenesis in vitro. Induction of the growth and tube formation of human microvascular endothelial cells through autocrine vascular endothelial growth factor. J. Biol. Chem. 272, 8723-8730. doi: 10.1074/jbc.272.13.8723

Yang, L., Liu, L., Xu, Z., Liao, W., Feng, D., Dong, X., et al. (2015). EBV-LMP1 targeted DNAzyme enhances radiosensitivity by inhibiting tumor angiogenesis via the JNKs/HIF-1 pathway in nasopharyngeal carcinoma. Oncotarget 6, 58045817. doi: 10.18632/oncotarget.3331

Yao, S., Hu, M., Hao, T., Li, W., Xue, X., Xue, M., et al. (2015). MiRNA-891a-5p mediates HIV-1 Tat and KSHV Orf-K1 synergistic induction of angiogenesis by activating NF-kappaB signaling. Nucleic Acids Res. 43, 9362-9378. doi: 10.1093/ nar/gkv988

Ye, F. C., Blackbourn, D. J., Mengel, M., Xie, J. P., Qian, L. W., Greene, W., et al. (2007). Kaposi's sarcoma-associated herpesvirus promotes angiogenesis by inducing angiopoietin-2 expression via AP-1 and Ets1. J. Virol. 81, 3980-3991. doi: 10.1128/JVI.02089-2086

Ye, F. C., Zhou, F. C., Nithianantham, S., Chandran, B., Yu, X. L., Weinberg, A., et al. (2013). Kaposi's sarcoma-associated herpesvirus induces rapid release of angiopoietin-2 from endothelial cells. J. Virol. 87, 6326-6335. doi: 10.1128/JVI. 03303-3312

Ye, J., Huang, J., He, Q., Zhao, W., Zhou, X., Zhang, Z., et al. (2018). Blockage of store-operated $\mathrm{Ca}(2+)$ entry antagonizes Epstein-Barr virus-promoted angiogenesis by inhibiting $\mathrm{Ca}(2+)$ signaling-regulated VEGF production in 
nasopharyngeal carcinoma. Cancer Manag. Res. 10, 1115-1124. doi: 10.2147/ CMAR.S159441

Yoo, J., Kang, J., Lee, H. N., Aguilar, B., Kafka, D., Lee, S., et al. (2010). Kaposin$\mathrm{B}$ enhances the PROX1 mRNA stability during lymphatic reprogramming of vascular endothelial cells by Kaposi's sarcoma herpes virus. PLoS Pathog. 6:e1001046. doi: 10.1371/journal.ppat.1001046

Yoon, C., Kim, J., Park, G., Kim, S., Kim, D., Hur, D. Y., et al. (2016). Delivery of miR-155 to retinal pigment epithelial cells mediated by Burkitt's lymphoma exosomes. Tumour Biol. 37, 313-321. doi: 10.1007/s13277-015-3769-3764

Yoshizaki, T., Horikawa, T., Qing-Chun, R., Wakisaka, N., Takeshita, H., Sheen, T. S., et al. (2001). Induction of interleukin- 8 by Epstein-Barr virus latent membrane protein-1 and its correlation to angiogenesis in nasopharyngeal carcinoma. Clin. Cancer Res. 7, 1946-1951.

Yoshizaki, T., Sato, H., Furukawa, M., and Pagano, J. S. (1998). The expression of matrix metalloproteinase 9 is enhanced by Epstein-Barr virus latent membrane protein 1. Proc. Natl. Acad. Sci. U.S.A. 95, 3621-3626. doi: 10.1073/pnas.95.7. 3621

You, B., Le Tourneau, C., Chen, E. X., Wang, L., Jarvi, A., Bharadwaj, R. R., et al. (2012). A Phase II trial of erlotinib as maintenance treatment after gemcitabine plus platinum-based chemotherapy in patients with recurrent and/or metastatic nasopharyngeal carcinoma. Am. J. Clin. Oncol. 35, 255-260. doi: 10.1097/COC. 0b013e31820dbdcc

You, W. K., and McDonald, D. M. (2008). The hepatocyte growth factor/c-Met signaling pathway as a therapeutic target to inhibit angiogenesis. BMB Rep. 41, 833-839. doi: 10.5483/bmbrep.2008.41.12.833

Young, L. S., Yap, L. F., and Murray, P. G. (2016). Epstein-Barr virus: more than 50 years old and still providing surprises. Nat. Rev. Cancer 16:789. doi: $10.1038 /$ nrc. 2016.92

$\mathrm{Yu}$, B., and Wang, S. (2018). Angio-LncRs: LncRNAs that regulate angiogenesis and vascular disease. Theranostics 8, 3654-3675. doi: 10.7150/thno.26024

Yu, X., Sha, J., Xiang, S., Qin, S., Conrad, P., Ghosh, S. K., et al. (2016). Suppression of KSHV-induced angiopoietin-2 inhibits angiogenesis, infiltration of inflammatory cells, and tumor growth. Cell Cycle 15, 2053-2065. doi: 10. 1080/15384101.2016.1196303

Zhang, Y. W., Su, Y., Volpert, O. V., and Vande Woude, G. F. (2003). Hepatocyte growth factor/scatter factor mediates angiogenesis through positive VEGF and negative thrombospondin 1 regulation. Proc. Natl. Acad. Sci. U.S.A. 100, 12718-12723. doi: 10.1073/pnas.2135113100

Zhao, B., Mar, J. C., Maruo, S., Lee, S., Gewurz, B. E., Johannsen, E., et al. (2011). Epstein-Barr virus nuclear antigen 3C regulated genes in lymphoblastoid cell lines. Proc. Natl. Acad. Sci. U.S.A. 108, 337-342. doi: 10.1073/pnas.10174 19108

Zhong, C., Xu, M., Wang, Y., Xu, J., and Yuan, Y. (2017). An APE1 inhibitor reveals critical roles of the redox function of APE1 in KSHV replication and pathogenic phenotypes. PLoS Pathog. 13:e1006289. doi: 10.1371/journal.ppat.1006289

Zhou, F., Xue, M., Qin, D., Zhu, X., Wang, C., Zhu, J., et al. (2013). HIV-1 Tat promotes Kaposi's sarcoma-associated herpesvirus (KSHV) vIL-6-induced angiogenesis and tumorigenesis by regulating PI3K/PTEN/AKT/GSK-3beta signaling pathway. PLoS One 8:e53145. doi: 10.1371/journal.pone.0053145

Zhu, X., Guo, Y., Yao, S., Yan, Q., Xue, M., Hao, T., et al. (2014). Synergy between Kaposi's sarcoma-associated herpesvirus (KSHV) vIL-6 and HIV-1 Nef protein in promotion of angiogenesis and oncogenesis: role of the AKT signaling pathway. Oncogene 33, 1986-1996. doi: 10.1038/onc.2013.136

Conflict of Interest Statement: The authors declare that the research was conducted in the absence of any commercial or financial relationships that could be construed as a potential conflict of interest.

Copyright (c) 2019 Rivera-Soto and Damania. This is an open-access article distributed under the terms of the Creative Commons Attribution License (CC BY). The use, distribution or reproduction in other forums is permitted, provided the original author(s) and the copyright owner(s) are credited and that the original publication in this journal is cited, in accordance with accepted academic practice. No use, distribution or reproduction is permitted which does not comply with these terms. 